\title{
A multipoint study of a substorm occurring on 7 December, 1992, and its theoretical implications
}

\author{
N. J. Fox ${ }^{1}$, S. W. H. Cowley ${ }^{2}$, V. N. Davda ${ }^{3}$, G. Enno ${ }^{4}$, E. Friis-Christensen ${ }^{5}$, R. A. Greenwald ${ }^{6}$, M. R. Hairston ${ }^{7}$, \\ M. Lester ${ }^{2}$, M. Lockwood ${ }^{3}$, H. Lühr ${ }^{8}$, D. K. Milling ${ }^{9}$, J. S. Murphree ${ }^{4}$, M. Pinnock ${ }^{10}$, G. D. Reeves ${ }^{11}$ \\ ${ }^{1}$ Laboratory for Extraterrestrial Physics, NASA/GSFC, Greenbelt, MD 20771, USA \\ E-mail: nicola.fox@gsfc.nasa.gov \\ ${ }^{2}$ Physics Department, University of Leicester, LE1 7RH, UK \\ ${ }^{3}$ Rutherford Appleton Laboratory, Chilton, Didcot, Oxfordshire OX11 0QX, UK \\ 4 Department of Physics and Astronomy, University of Calgary, Alberta, Canada T2N 1N4 \\ ${ }^{5}$ Danish Space Research Institute, Juliane Marie Verj 30, DK-2100 Copenhagen, Denmark \\ ${ }^{6}$ John Hopkins University, Applied Physics Laboratory, Laurel, MD 20723, USA \\ ${ }^{7}$ University of Texas at Dallas, Richardson, TX 75080, USA \\ ${ }^{8}$ GeoForschungsZentrum Potsdam, Telegrafenberg, D-14473 Potsdam, Germany \\ ${ }^{9}$ Department of Physics, University of York, York YO1 5DD, UK \\ ${ }^{10}$ British Antarctic Survey, Cambridge CB3 0ET, UK \\ ${ }^{11}$ Los Alamos National Laboratory, Los Alamos, NM 87545, USA
}

Received: 2 April 1998 / Revised: 8 March 1999 / Accepted: 12 March 1999

\begin{abstract}
On 7 December 1992, a moderate substorm was observed by a variety of satellites and ground-based instruments. Ionospheric flows were monitored near dusk by the Goose Bay HF radar and near midnight by the EISCAT radar. The observed flows are compared here with magnetometer observations by the IMAGE array in Scandinavia and the two Greenland chains, the auroral distribution observed by Freja and the substorm cycle observations by the SABRE radar, the SAMNET magnetometer array and LANL geosynchronous satellites. Data from Galileo Earth-encounter II are used to estimate the IMF $B_{z}$ component. The data presented show that the substorm onset electrojet at midnight was confined to closed field lines equatorward of the preexisting convection reversal boundaries observed in the dusk and midnight regions. No evidence of substantial closure of open flux was detected following this substorm onset. Indeed the convection reversal boundary on the duskside continued to expand equatorward after onset due to the continued presence of strong southward IMF, such that growth and expansion phase features were simultaneously present. Clear indications of closure of open flux were not observed until a subsequent substorm intensification $25 \mathrm{~min}$ after the initial onset. After this time, the substorm auroral bulge in the nightside hours propagated well poleward of the pre-existing convection reversal boundary, and strong flow perturbations were observed by the Goose Bay radar, indicative of flows driven by reconnection in the tail.
\end{abstract}

Correspondence to: N. J. Fox
Key words. Ionosphere (auroral ionosphere; plasma convection) - Magnetospheric physics (storms and substorms)

\section{Introduction}

The onset of a magnetospheric substorm, marking the transition from the growth to the expansion phase, is defined as the beginning of the explosive brightening and expansion of the aurora. As the Akasofu (1964) model had only two substorm phases, expansion and recovery, expansion, onset was the first event during a substorm. With the addition of the growth phase (McPherron, 1970) it was recognised that the substorm cycle began not at onset, but typically 30-60 min earlier when the rate of dayside flux production increased (usually due to a southward turning of the IMF). The term onset was retained for the commencement of the auroral and current features described by Akasofu (1964), and subsequently became associated with the commencement of the reconnection of open flux in the tail, which closes the open flux accumulated in the growth phase. The main assumptions of the near-Earth neutral line (NENL) substorm model were that the onset of near-Earth tail reconnection caused the onset of the expansion phase, and that this reconnection rate is sufficiently rapid that the plasmoid is pinched off within a few minutes such that open lobe flux then begins to be closed (Hones, 1979). More recent evidence, however, suggests that there may be a significant delay between the expansion phase onset and the closure of open flux. Although Nagai et al. (1998) have shown that reconnection generally commences between 
20-30 $R_{E}$ downtail within a few minutes of substorm onset, it appears nevertheless that a substantial interval may elapse before the resulting plasmoid is pinched off and open lobe flux starts to be reconnected. For example, Maynard et al. (1997) using an extensive dataset including Geotail data, have inferred that open flux closure did not begin until $15 \mathrm{~min}$ after onset in one event, and $40 \mathrm{~min}$ after onset in another. In a study of ionospheric flows using the AMIE technique, Taylor et al. (1996) also inferred that open flux typically did not start to decrease until 20 min after substorm onset. Correspondingly, the expansion of the auroral bulge is observed to originate on the most equatorward discrete arc, which is usually located well equatorward of the open/closed field line boundary, as implied by Akasofu's (1964) original picture (see also Galperin and Feldstein, 1991), and subsequently confirmed by Viking imager data (Murphree and Cogger, 1992; Elphinstone and Hearn, 1992; Cogger and Elphinstone, 1992). The latter show that the auroral bulge often reaches the open/closed field line boundary towards the end of the expansion phase (see also, for example, Lopez et al., 1992), at which time the poleward edge often brightens and becomes more active whilst the aurora in the middle of the bulge often fade, leading to a "double oval" configuration.

In this work we will analyse a substorm which occurred during the second Galileo Earth-encounter and will show that in this case open flux closure was delayed relative to substorm onset by more than $25 \mathrm{~min}$. This will be inferred from a dataset combining ground magnetic records, radar observations of ionospheric flow and satellite measurements.

\section{Instrumentation}

In this study we will combine together data from a network of ground-based instruments with satellite observations to study the evolution of a substorm on 7 December, 1992. Data from the IMAGE, Greenland and SAMNET magnetometer chains and Los Alamos National Laboratory (LANL) spacecraft in geosynchronous orbit are used to detect the substorm onset and subsequent intensification. The location and motion of the convection reversal boundary were monitored by the EISCAT incoherent scatter radar, Goose Bay HF radar, SABRE VHF radar and the Defense Meteorological Satellite Program (DMSP) satellites. Unfortunately, there are no interplanetary magnetic field (IMF) data for the interval studied owing to a gap in the IMP-8 data record. However, Galileo was located in the magnetosheath during its second Earth-encounter and the data obtained can be used to deduce the orientation of the IMF. Figure 1 shows the positions of the ground stations used in this study together with the footprints of the LANL satellites. This figure illustrates the broad coverage of the observations, extending over $6 \mathrm{~h}$ of magnetic local time (MLT) and from sub-auroral latitudes to within the polar cap. A brief description of the data sources is given.
1. Data from the EISCAT radar were obtained using the SP-UK-CONV experiment, in which the VHF radar was used in a split-beam mode. One pair of panels of the antenna were phased such that the beam pointed along an azimuth $344.8^{\circ}$ to the east of geographic north (west beam) and the beam of the remaining pair to $359.8^{\circ}$ (east beam), both at an elevation of $30^{\circ}$. In this mode, therefore, the VHF system provides two independent radars operating with two different fixed beam directions. The data are taken simultaneously at each azimuth with $10 \mathrm{~s}$ resolution. Echoes are received from range gates $65.3 \mathrm{~km}$ in length along the beam passing through the F-region ionosphere, covering invariant latitudes $71^{\circ}-78^{\circ}$. The data are analysed using an " $L$ shell fitting" technique to estimate the ionospheric flow magnitude and direction from line-of-sight velocities, assuming that the flow is the same along the $L$-shells between the two azimuths and that the magnetic field parallel flow is negligible. The data have been analysed for the $10 \mathrm{~s}$ preintegration periods with no post integration. The MLT of the CONV field-of-view is approximately UT $+2.25 \mathrm{~h}$ for azimuth $344.8^{\circ}$ and $\mathrm{UT}+2.75 \mathrm{~h}$ for $359.8^{\circ}$.

2. The Goose Bay HF coherent backscatter radar has been described by Greenwald et al. (1985) and now forms part of the SuperDARN network (Greenwald et al., 1996). The radar measures the power and line-ofsight Doppler spectral characteristics of signals backscattered from irregularities in the polar F-region. The Goose Bay radar field-of-view covers the range of invariant latitudes $65^{\circ}-85^{\circ}$ and spans $4 \mathrm{~h}$ of local time. The centre of the field-of-view is at a MLT given approximately by UT $-3 \mathrm{~h}$. Data from the 16 beam directions are recorded over successive $6 \mathrm{~s}$ integration periods, such that the field-of-view is scanned every $96 \mathrm{~s}$. Flow vectors are derived where sufficient backscatter intensity is received by the $L$-shell fitting technique (Ruohoniemi et al., 1989; Freeman et al., 1991).

3. At the time of this study the SABRE radar comprised a monostatic VHF radar located at Wick, with a field-of-view centred on an MLT of $\sim$ UT $+1 \mathrm{~h}$ and covering an invariant latitude range of $61^{\circ}-65^{\circ}$. The temporal resolution was typically $20 \mathrm{~s}$. The signal received by a VHF coherent radar has been scattered by E-region irregularities which have a drift speed related to the convection flow speed. A more complete description of the SABRE auroral backscatter system is given by Nielsen et al. (1983).

4. SAMNET is an array comprising seven triaxial fluxgate magnetometers which cover midlatitudes in western Europe (Yeoman et al., 1990). These data are used to identify the occurrence of Pi2 pulsations and thus the onset of substorms.

5. The Greenland magnetometer network consists of two latitudinal chains of magnetometers located along the east and west coasts of Greenland (Wilhjelm and Friis-Christensen, 1976). The east coast chain stretches from $70^{\circ}$ to $81^{\circ}$ in geomagnetic latitude and $56^{\circ}$ to $111^{\circ}$ in geomagnetic longitude. The corresponding ranges for the west coast chain are from $68^{\circ}$ to $86^{\circ}$ in latitude and $36^{\circ}$ to $47^{\circ}$ in longitude. Each station has a three- 


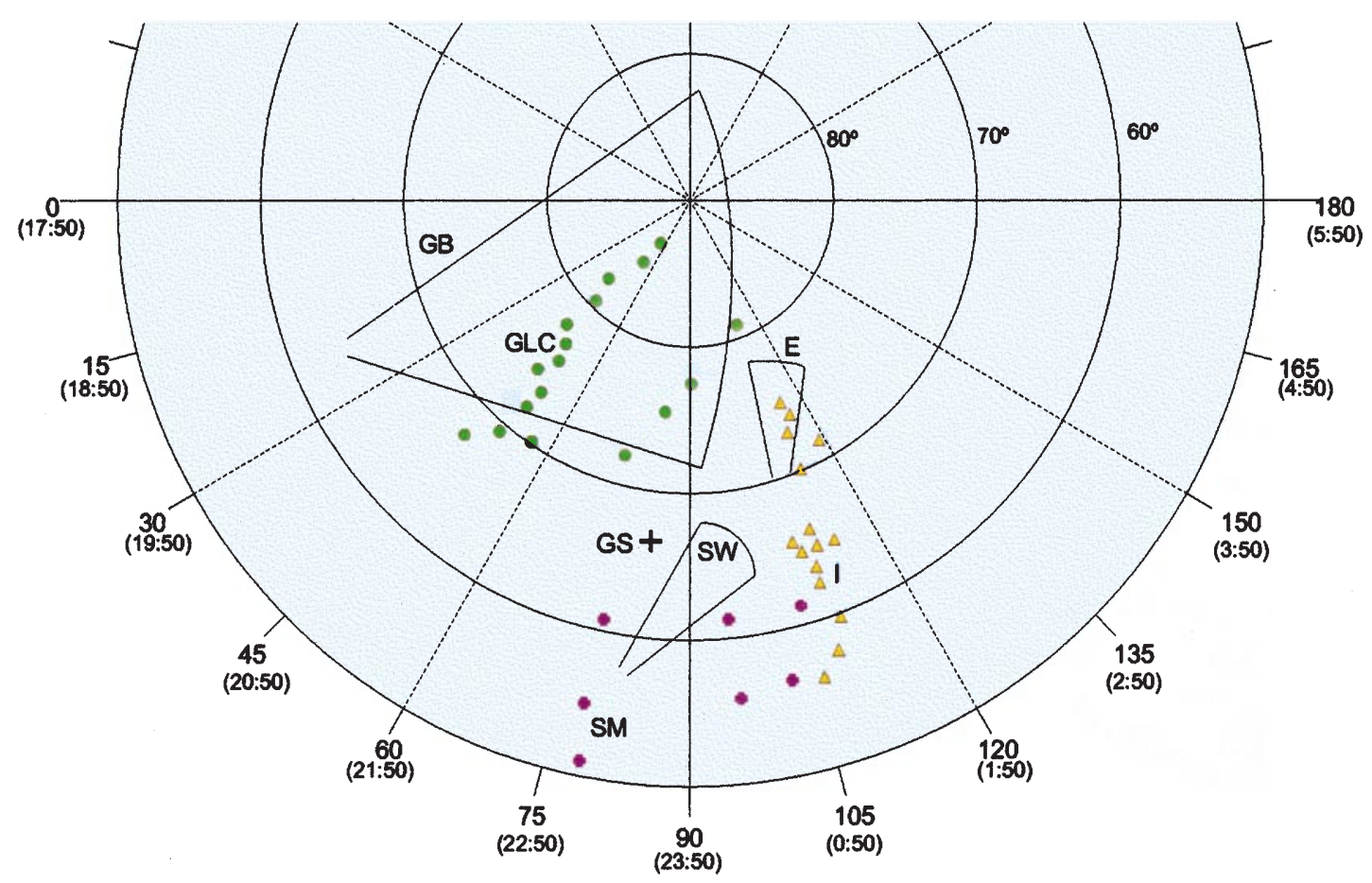

Fig. 1. Geomagnetic latitude and longitude of the ground-based stations used. The MLT is indicated in brackets corresponding to 2245 UT, which is one of the principal periods of study. The field-of-view of the Goose Bay radar is labelled $G B$, the two beams for the EISCAT CP-4-B experiment $E$ and the SABRE beam at

component fluxgate magnetometer which operates at $20 \mathrm{~s}$ resolution. The perturbations from the quiet-day diurnal variations are given here in terms of the three component directions, $H, E$ and $Z$, where $H$ is positive towards the north along the local magnetic meridian, $E$ is positive towards the east perpendicular to the local meridian, and $Z$ is positive in the vertically downwards direction.

6. The IMAGE magnetometer network is located in Scandinavia with stations from mid-latitudes up to Svalbard (Lühr et al., 1998). The entire network extends latitudinally from $56^{\circ}$ to $75^{\circ}$ and longitudinally from $106^{\circ}$ to $119^{\circ}$ (geomagnetic coordinates). Each of the instruments in the network is a triaxial fluxgate magnetometer similar to those used in the Greenland chain, but the field perturbation components given here are the three orthogonal components, $X$, horizontal geographic northward, $Y$, horizontal geographic eastward, and $Z$, vertically downwards.

7. The Los Alamos particle analyser instruments CPA and SOPA obtained the geosynchronous orbit energetic particle data presented here. The spacecraft used in this study are 1984-129 at a local time of $\mathrm{UT}+06: 54 \mathrm{~h}$ and 1990-095 at UT $+00: 31 \mathrm{~h}$. The CPA instruments on 1984-129 measure electrons in the energy range $30-300 \mathrm{keV}$ and ions with energies 72 $573 \mathrm{keV}$. The SOPA instruments aboard 1990-095 measure electrons in the energy range $50-315 \mathrm{keV}$ and ions with energies $113-670 \mathrm{keV}$. A more detailed description of the Los Alamos particle instruments is
Wick $S W$. The solid circles represent the positions of the magnetometers in the Greenland Chain $(G L C)$, IMAGE $(I)$ and SAMNET $(S M)$ networks respectively. The black cross and the letters $G S$ indicate the magnetic footprint of the geosynchronous satellite 1990-095

given by Higbie et al. (1978) and Belian et al. (1992). In this study we use the data to observe particle injections which identify onset (Baker et al., 1978).

8. During the interval reviewed here, magnetic field data from the Galileo spacecraft, at the time of its second Earth encounter, were used to monitor the magnetic field in the Earth's magnetosheath. Galileo was located at GSM coordinates $(X, Y, Z) \sim(-70,40$, $26 R_{E}$ ), sufficiently far from the centre of the tail that the magnetic field data can be used as a reasonable proxy for the IMF. The Galileo magnetometers are described in Kivelson et al. (1992).

9. The DMSP spacecraft are a series of polar orbiting satellites designed to observe the weather on Earth and to monitor the near-Earth space environment at $840 \mathrm{~km}$. We have used ionospheric velocity measurements obtained by the F10 and F11 spacecraft to derive the potential along the spacecraft track and hence the convection reversal boundaries. The orbital period of the satellites is $\sim 103 \mathrm{~min}$ and each of the polar passes (magnetic latitudes exceeding $50^{\circ}$ ) takes $18-20 \mathrm{~min}$.

10. FREJA, a Swedish and German scientific satellite, was launched on 6 October, 1992. Freja orbits at an altitude ranging between about 600 and $1750 \mathrm{~km}$ with an orbital inclination of $63^{\circ}$. The payload includes an auroral imager comprising two cameras. The one presented here monitors the molecular nitrogen Lyman-Birge-Hopfield (LBH) emissions and has a passband from 134 to $180 \mathrm{~nm}$ (Murphree et al., 1994). The image contained here is a composite of five separate 
images taken at two minute intervals, where each of the separate images has an overall field-of-view of $29.4^{\circ}$ by $109.2^{\circ}$.

\section{Observations}

Data from the Galileo Earth-encounter II for 21 UT on 7 December to 01 UT on 8 December, 1992, are plotted in Fig. 2. When these data were taken, the satellite was located in the magnetosheath $\sim 72 R_{E}$ downtail. By taking a value of $450 \mathrm{~km} \mathrm{~s}^{-1}$ for the solar wind speed (from the Geotail record), a delay of $\sim 20$ min can be estimated as the time taken for effects at the nose of the magnetosphere to be detected by Galileo. For the first hour of this interval, the magnetic field is mainly northward pointing with $B_{y}$ negative and $B_{x}$ positive. Shortly after 2200 UT, a southward turning occurred in the $B_{z}$ component ( $\sim 2140$ UT at the subsolar magne- topause). Subsequently $B_{z}$ decreased slowly until near 2235 UT ( 2215 UT at the subsolar magnetopause) when it suddenly dropped to $-20 \mathrm{nT}$. Prior to this time the $B_{y}$ component was strongly negative (around $-25 \mathrm{nT}$ ) while $B_{x}$ was near zero. After 2235 UT $B_{y}$ declined sharply towards zero such that the field was directed nearly due south in the GSM frame for about 20 min. At 2255 UT $(\sim 2235$ UT at the subsolar magnetopause), $B_{z}$ suddenly turned northward and remained so for the following $25 \mathrm{~min}$, except when it briefly returned to zero at $\sim 2257$ UT. From 2315 to 0015 UT the $B_{z}$ field was variable but typically weakly negative. During the whole of the period after $\sim 2255 \mathrm{UT}, B_{x}$ was positive and $B_{y}$ strongly negative. For the remainder of this study these times will be quoted in terms of the effect at the subsolar magnetopause and not detection by Galileo.

Turning now to the corresponding ground-based data, we shall now examine the magnetometer and radar
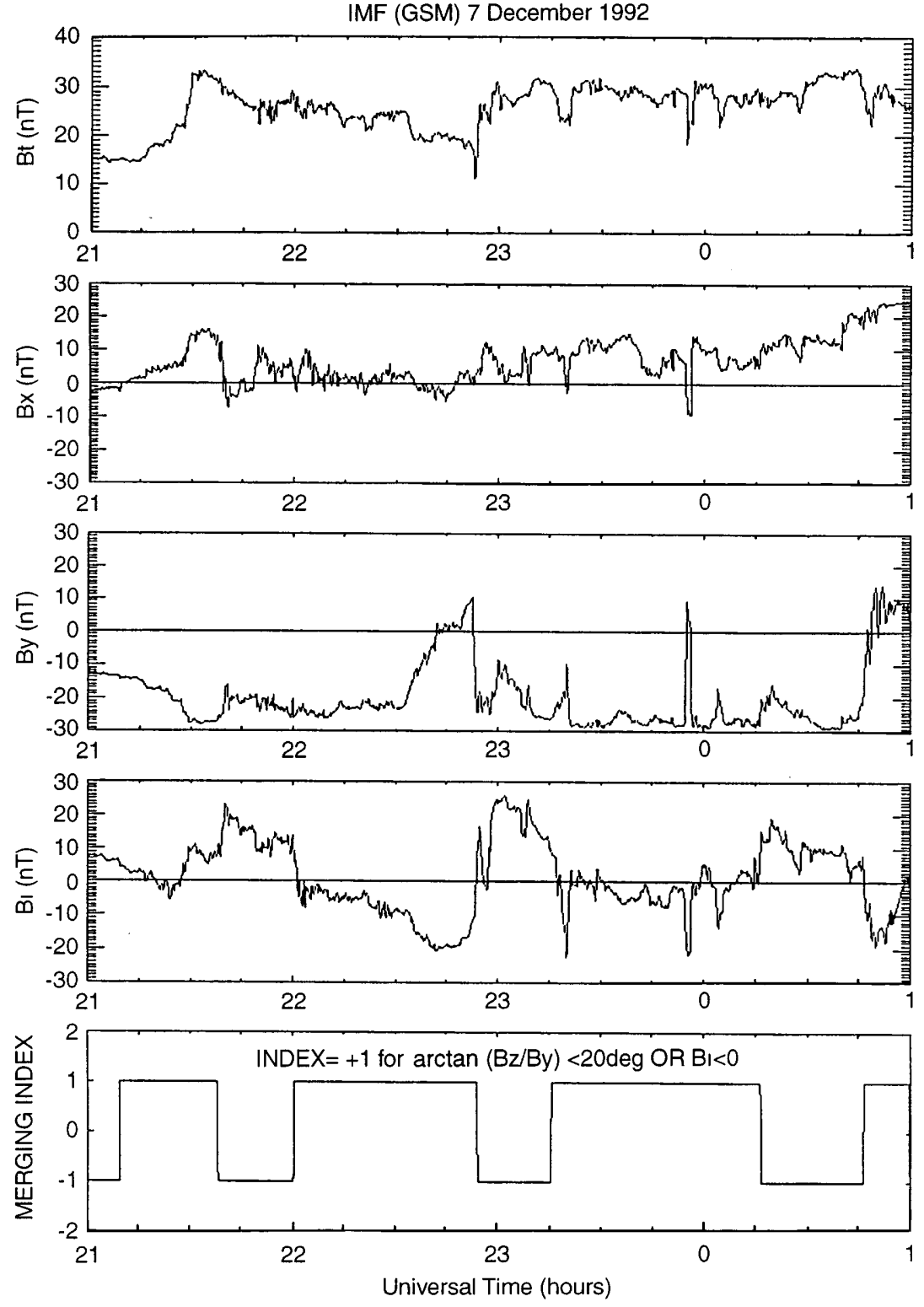

Fig. 2. Magnetic data from Galileo Earth-encounter II in GSM co-ordinates. The data shown are from 21 UT, 7 December, 1992, to 01 UT, 8 December, 1992 and are averaged over $20 \mathrm{~s}$. During the time period reviewed, Galileo was located in the magnetosheath at GSM coordinates $\left(X, Y, Z \sim-70,40,26 R_{E}\right.$ ), sufficiently far from the centre of the tail that the magnetic field data can be used to indicate the strength and orientation of the IMF. The bottom panel indicates the merging index. A value of 1 denotes that the conditions are favourable for low-latitude dayside reconnection, i.e. the IMF $B_{z}$ is southward or the magnetic shear angle between the subsolar magnetospheric field and the IMF was only $\sim 70^{\circ}$ when the IMF $B_{z}$ was northward 
observations. The backscatter intensity detected by the SABRE radar between 21 and 23 UT is plotted in Fig. 3 as a function of range and UT. It shows an intensification of the backscatter at 2130 UT, which rapidly expanded equatorward starting at 2200 UT. We infer that this expansion was a response to the southward turning of the IMF with a delay of $20 \mathrm{~min}$, and interpret the equatorward motion as a growth phase signature. A similar phenomenon was reported by Lester et al. (1993) during the SUNDIAL campaign when the onset of backscatter was detected before any substorm onset signatures and was thus assumed to be associated with the southward turning of the IMF. The apparent bifurcation of the backscatter band which appears at around 2210 UT is probably due to an instrumental effect known as Lloyd's mirror (Mattin and Jones, 1985). The remainder of this figure will be described later, after we have introduced the adjacent magnetic observations at the IMAGE chain.

The $X$ - and $Z$-components of the magnetic field detected by the IMAGE magnetometers are plotted in Fig. 4. These data show that there was very little magnetic activity during the initial period of modest southward IMF $B_{z}, 2140-2215$ UT (Fig. 2), including the nightside response to the growth phase (starting at 2200 UT) described already. The onset of the first bay in the $X$-component can be seen at $2215 \mathrm{UT}$, indicated by the first dash-dot line in Fig. 4a. This occurred around the time of the large increase in southward IMF $B_{z}$ to $-20 \mathrm{nT}$ at the subsolar magnetopause (Fig. 2) and the onset of the Pi2 $\mathrm{s}$ detected by SAMNET, shown in Fig. 5. Both the $X$ - and $Z$-components (Fig. 4a, b) of the magnetic deflections seen by the IMAGE array provide evidence that the electrojet was approximately

DETAILED RANGE - TIME - INTENSITY WICK BEAM 57 December 1992 [342]

INTENSITY $(\mathrm{dB})$

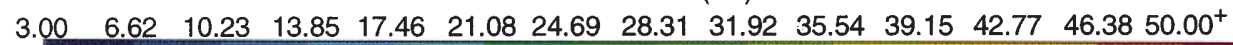

RX GAIN SETTING
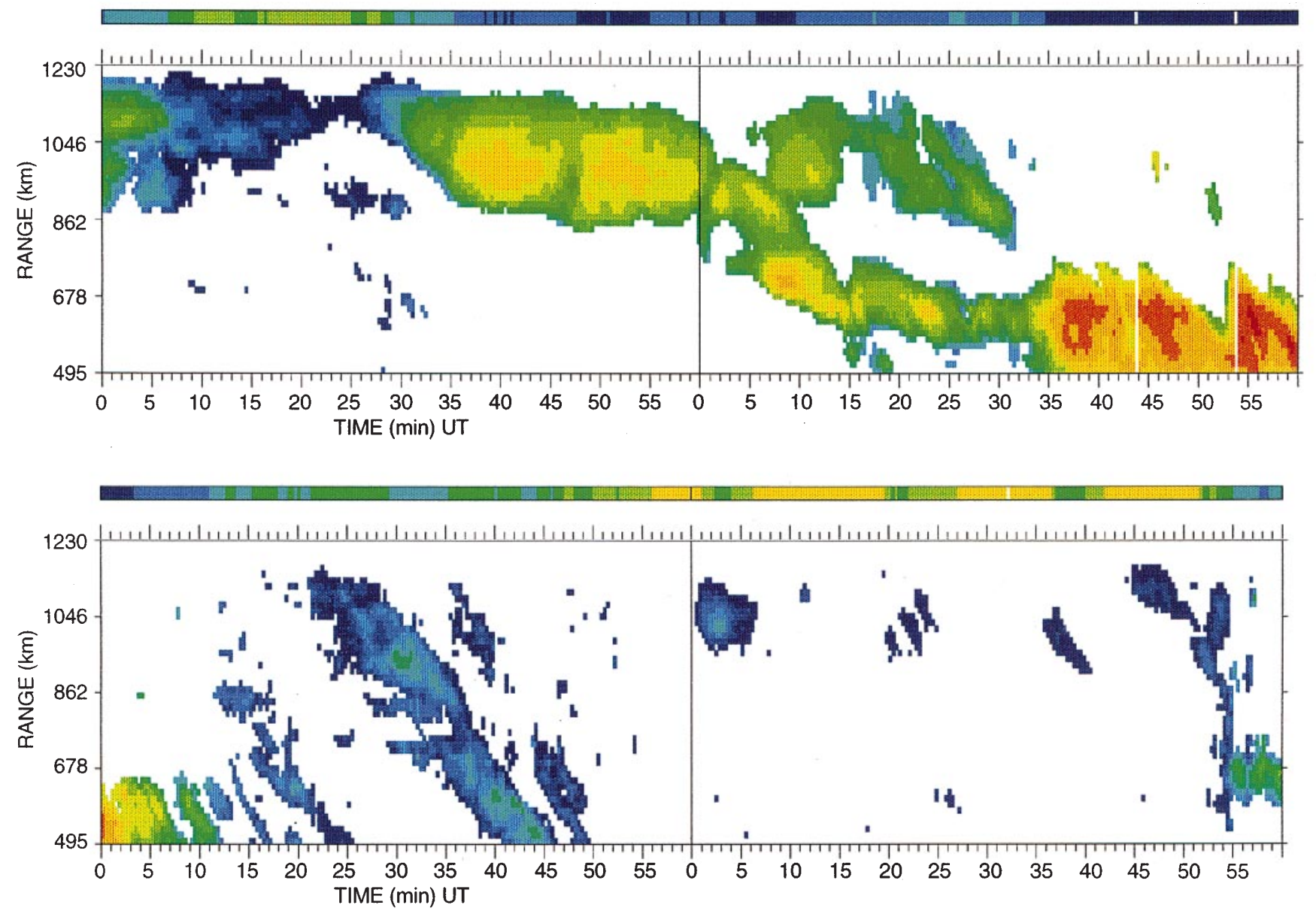

Fig. 3. Range time intensity plot produced using data from the SABRE radar for 21 UT, 7 December 1992-01 UT, 8 December 1992. Only one of the central beams, beam 5, of the Wick radar is used here. It is a summary plot used to indicate the existence of backscatter. The colour scale represents the intensity of the backscatter 


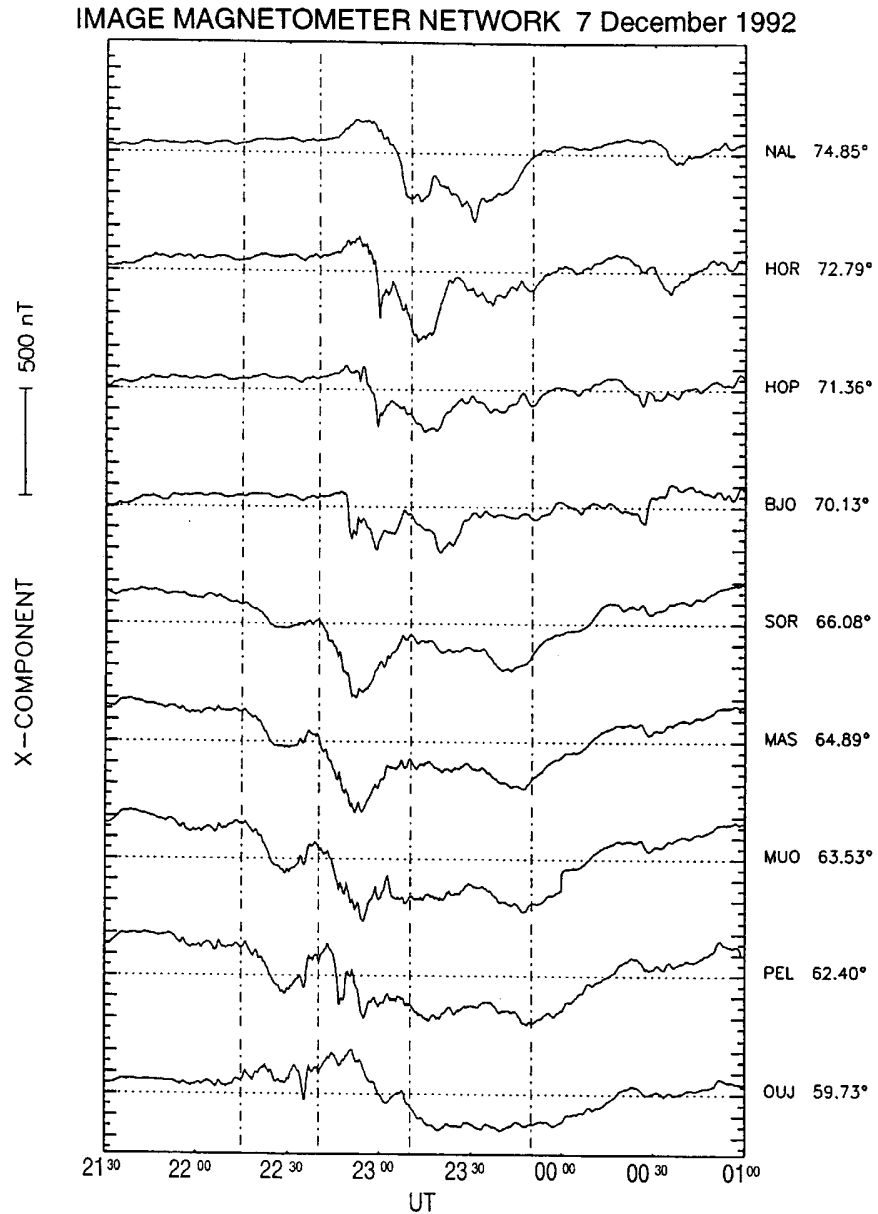

Fig. 4a, b. IMAGE magnetometer chain data for 7 December-8 December 1992. Four hours of data are shown as indicated by the UT at the bottom of each panel. a Shows the $X$-component of the magnetic field and $\mathbf{b}$ the $Z$-component. The station names and their magnetic latitudes are shown between the plots. The vertical dash-dot lines

centred at station PEL (62.4 $4^{\circ}$ latitude) at this time; as well as the peak $X$ component being detected at PEL, there was a positive $Z$ deflection in the stations north of this station and a negative deflection to the south. Shortly after the expansion phase onset, the poleward edge of the backscatter band at SABRE (Fig. 3) contracted equatorward, starting at about 2220 UT. This may have been an effect of the substorm electrojet entering the radar field of view to the west of IMAGE (Fig. 1) where a reduction in flow speed inhibits the generation of E-region irregularities and hence radar backscatter (Inhester et al., 1981). Since the SABRE field of view was located just prior to midnight at this time, and the reduction of the backscatter encroached from the east, the implication is that the onset began in the post-midnight sector in the vicinity of the IMAGE chain and propagated westward to SABRE.

Returning now to the IMAGE data, it can be seen that the initial disturbance intensified over an interval of $\sim 15$ min before starting to decay. This was followed by an intensification at $\sim 2240$ UT (second dash-dot line in Fig. 4a) centred around MAS $\left(64.9^{\circ}\right)$, which coincided approximately with the northward turning of the IMF

\section{IMAGE MAGNETOMETER NETWORK 7 December 1992}

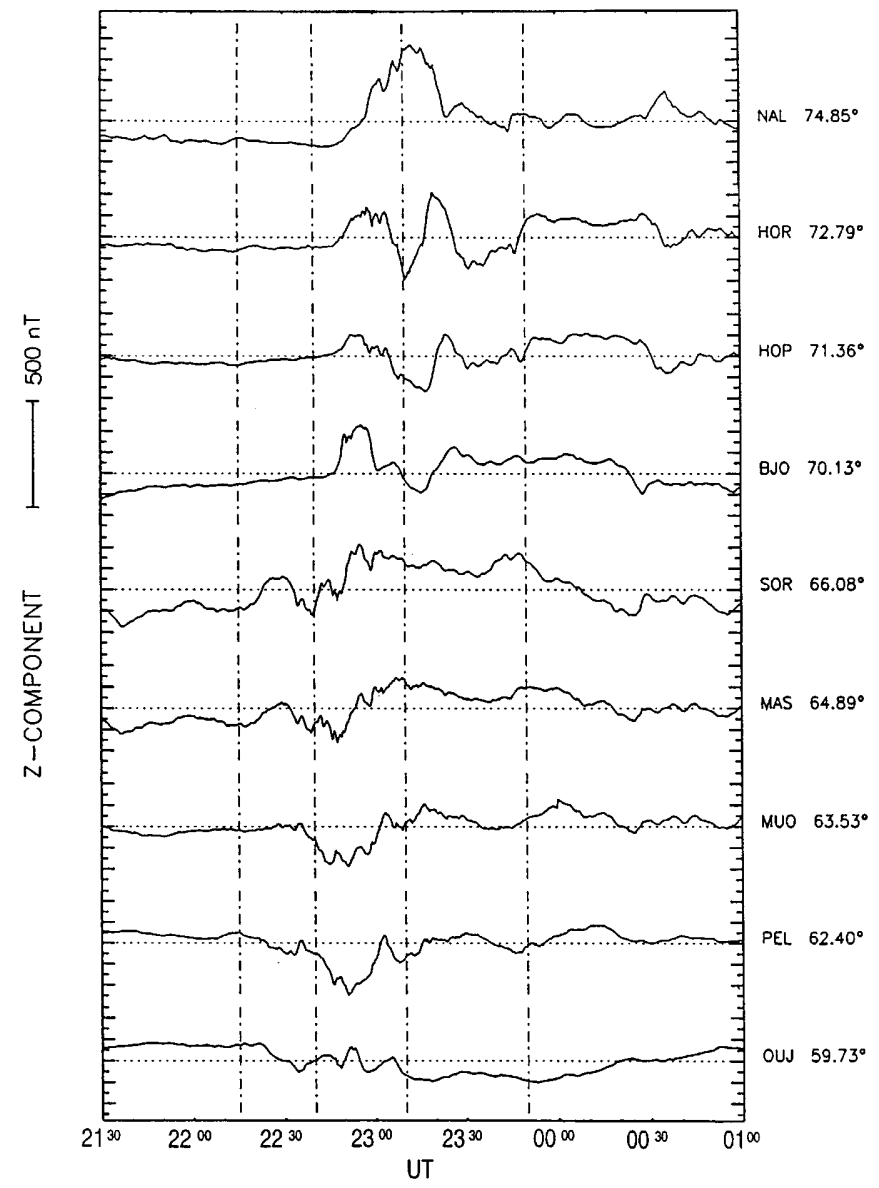

indicate the key substorm timings in this study, 2215 UT was substorm onset; 2240 UT the intensification; 2310 UT corresponds to the time when the "double oval" was well established; and 2350 UT was substorm recovery

at the nose, as detected by Galileo (Fig. 2). An associated $\mathrm{Pi} 2$ enhancement was also seen in the $D$ component of the SAMNET data (Fig. 5). This intensification resulted in a poleward expansion of the substorm disturbed region, which reached the Svalbard magnetometers (BJO $\left(70.1^{\circ}\right)$, HOP $\left(71.4^{\circ}\right)$, HOR $\left(72.8^{\circ}\right)$ and NAL $\left(74.9^{\circ}\right)$ ) after $\sim 2250$ UT. At about this time, the magnetic disturbance at the latitude of the original intensification, centred at MAS, started to recover, while those poleward and equatorward were intensifying so that a "double oval" configuration in the magnetic perturbations had formed by $\sim 2300$ UT. Recovery of the poleward part of the magnetic disturbance was in progress by 2340 UT and of the equatorward currents by 2350 UT.

$H$-component data from the Greenland magnetometer chain are plotted in Fig. 6. No perturbations were observed at any of the Greenland chain stations in response to the substorm onset detected by IMAGE at 2215 UT. This shows that the initial onset electrojet did not extend westward to the 20 MLT sector, monitored by the lower latitude Greenland stations (NAQ and FHB). The east coast stations are located at latitudes 

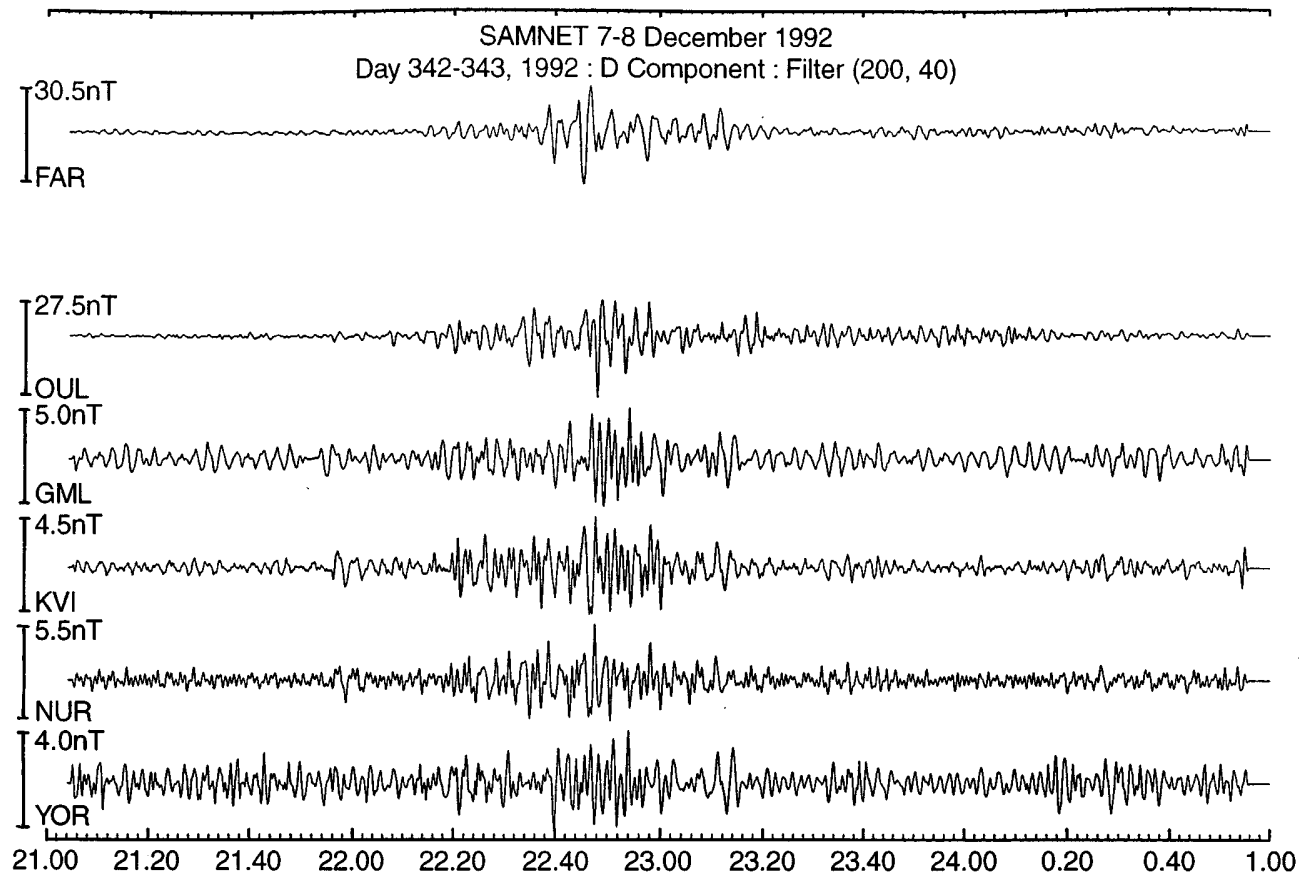

SAMNET 7-8 December 1992

Day 342-343, 1992 : H Component : Filter $(200,40)$

IFAR

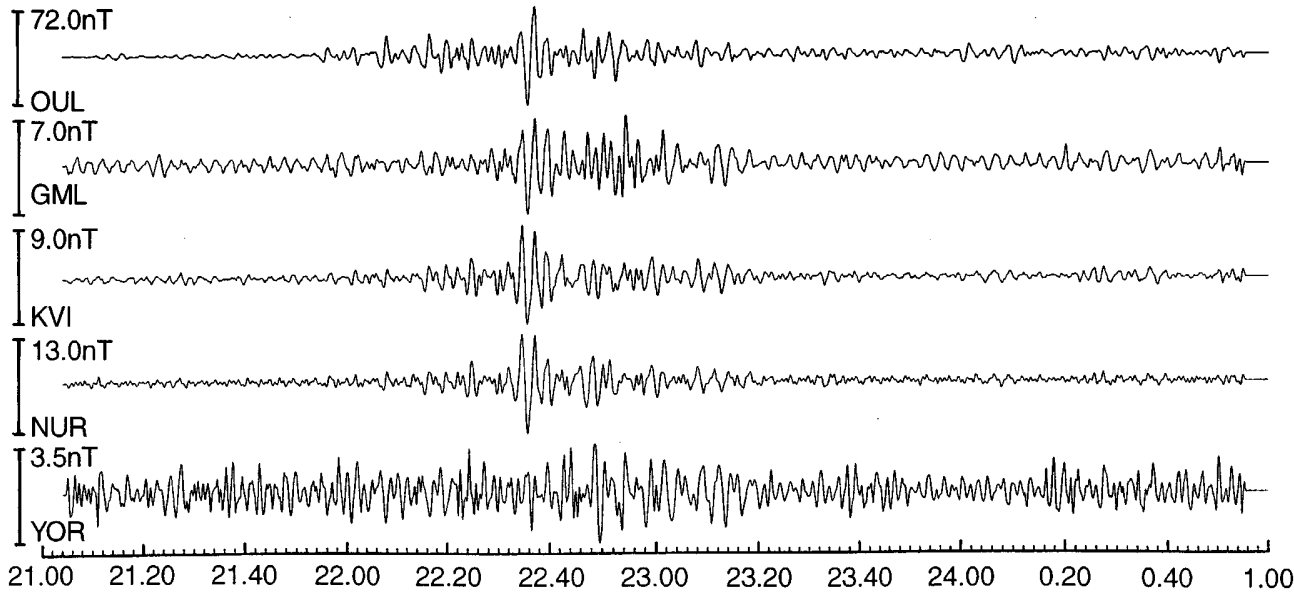

Fig. 5. Data from the SAMNET magnetometers for $21 \mathrm{UT}$, 7 December 1992-01 UT, 8 December 1992. The data are the filtered $H$ (upper panel) and $D$ (lower panel) components of the magnetic field, using a band-pass filter between 40 and $200 \mathrm{~s}$ too high to observe the onset (since the perturbations did not reach $\mathrm{BJO}$ at $70^{\circ}$ at IMAGE), but examination of data from the Leirvogur station on Iceland (not shown) at $66^{\circ}$ invariant latitude and MLT of UT-0:30, however, also did not observe any clear signatures associated with the initial onset, showing that the electrojet was confined eastward of about 21:45 MLT. The onset of negative bays was seen after $\sim 2245$ UT in the lowest latitude stations of the east coast Greenland chain (AMK $\sim 70^{\circ}$, and $\mathrm{SCO} \sim 72^{\circ}$ ) in the pre-midnight sector, about 5 minutes after the intensification detected by IMAGE as discussed (Fig. 4). The disturbance subsequently propagated poleward similarly to the IMAGE chain, reaching DNB $\left(\sim 75^{\circ}\right)$ at 2305 UT and DMH $\left(\sim 77^{\circ}\right)$ shortly thereafter. The westward electrojet did not reach station NRD $\left(81^{\circ}\right)$, however. The magnetometer stations on the west coast $(\sim 21-22$ MLT) observed no significant perturbations before $\sim 2300$ UT when weak negative bays appeared at latitudes between 70 and $75^{\circ}$. This shows that the substorm westward electrojet did not expand into this magnetic local time sector until late in the expansion phase development.

The relationship between the magnetic observations described already and the substorm disturbed region is 

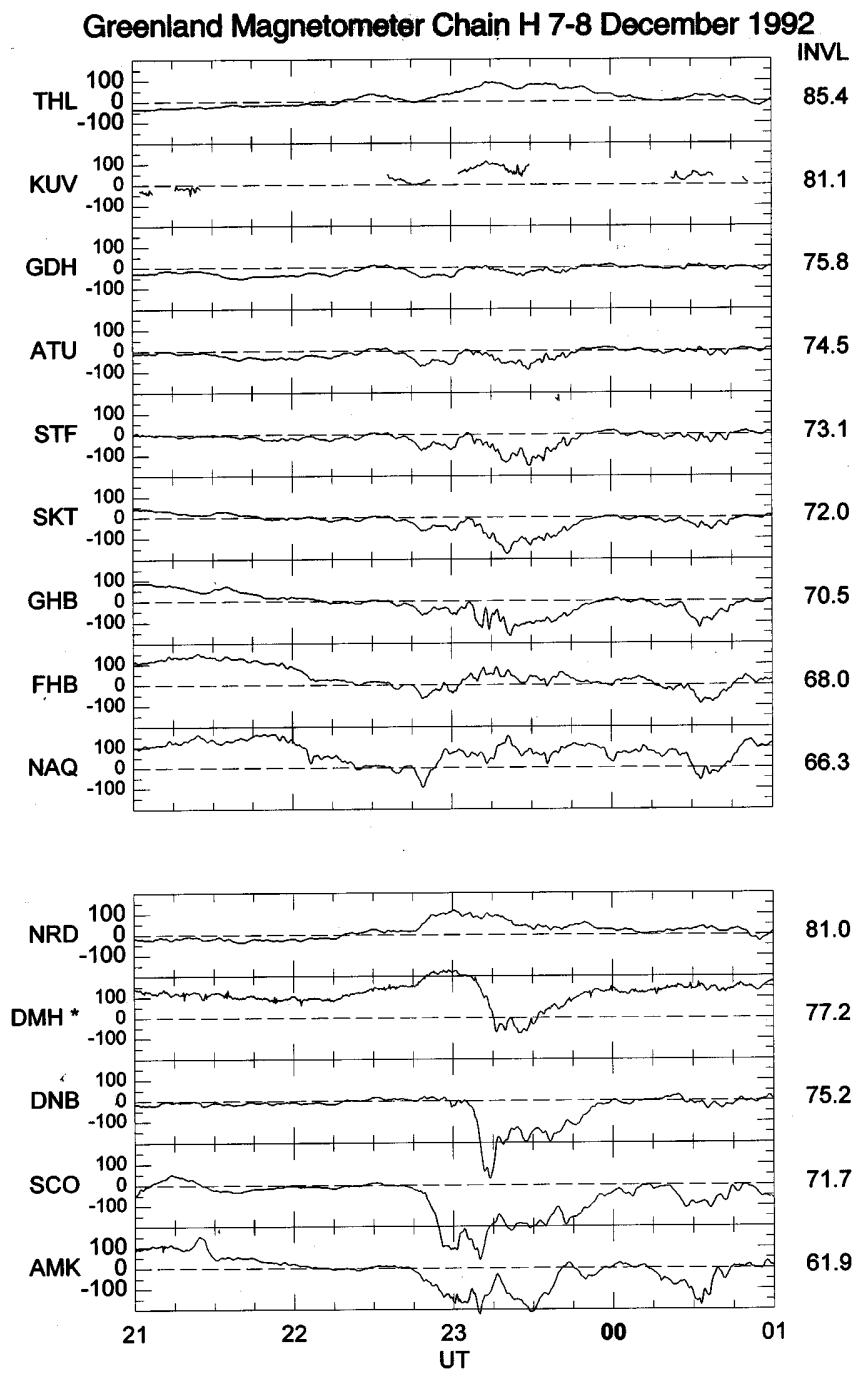

Fig. 6. The two panels show magnetic field data from the Greenland magnetometer chain for 21 UT, 7 December, 1992-01 UT, 8 December, 1992. The top panel is $H$-component data from the west coast chain (invariant latitudes $66.3-85.4^{\circ}$ ) and the bottom panel from the east coast chain (latitudes $52.7-81.0^{\circ}$ )

illustrated in Fig. 7, where the location of the magnetometer stations are superposed, together with the fieldsof-view of the various radars used in this study, on an auroral image from the Freja spacecraft. The image is a composite of consecutive UV images obtained in the period 2329-2339 UT. This period corresponds to the interval just prior to the onset of recovery of the disturbance at the IMAGE meridian when the double current structure was still well developed but starting to decline (Fig. 4). The images cover a region from the post-noon oval on the left, through dusk, and towards midnight on the right, though not quite reaching the meridian of the IMAGE chain in the early postmidnight hours $(\sim 2$ MLT). It can be seen that the nightside auroral distribution was very broad, extending from an equatorward boundary at a magnetic latitude of $\sim 60^{\circ}$ poleward to $\sim 73^{\circ}$, this spanning essentially the same latitude range as the two-component current system observed on the IMAGE meridian just to its east. It can also be seen that the auroral bulge does not quite reach the west coast stations of the Greenland magnetometer chain, thus explaining the lack of major magnetic perturbations on this meridian. It does, however, encompass the equatorward part of the eastern chain, although not extending to the poleward stations.

The LANL geosynchronous satellites detected particle injections around the time of the onset signatures seen by IMAGE and SAMNET at 2215 UT (Figs. 4 and 5). At $\sim 2218$ UT, spacecraft 1990-095 (22:51 MLT) detected a dispersionless proton injection (Fig. 8b), followed by a weak dispersed electron injection (Fig. 8a) which implies that the satellite was located just to the west of the injection region. The positioning of this spacecraft with respect to the injection region is in good agreement with the fact that the Iceland and Greenland west magnetometer chains were too far west to observe the perturbations detected by IMAGE associated with the substorm onset at 2215 UT. We saw that at $\sim 2240$ UT there was an intensification of magnetic perturbations at IMAGE, and a Pi2 at SAMNET. The geosynchronous satellites also detected particle injections around this time. Spacecraft 1990-095 detected a rise in the proton flux at $\sim 2242$ UT and electron flux at $\sim 2248$ UT (23:19 MLT). Both the electron and proton injections appeared to be dispersionless (Fig. 8a, b). This implies that the satellite was located within the MLT of the injection region at this time. Spacecraft 1984-129 located at 05:44 MLT (data not shown) also detected dispersed electron and proton injections two minutes later at $2250 \mathrm{UT}$. The dispersion curves for these injections appeared to be associated with the injections detected by 1990-095 at 2248 UT.

Summarising the data discussed in Figs. 2-8, we can deduce that a cycle of substorm activity occurred between $\sim 2140$ UT and $\sim 0030$ UT. The start of the growth phase was determined to be at $\sim 2140$ UT when we infer that the $B_{z}$ component of the IMF turned south at the subsolar magnetopause (Galileo data in Fig. 2), such that subsequently the SABRE radar (Fig. 3) detected a band of increased backscatter which expanded equatorward, starting at 2200 UT. Expansion phase onset signatures were seen by the IMAGE and SAMNET magnetometer chains at $\sim 2215$ UT with the LANL satellite 1990-095 detecting a dispersionless ion injection slightly later at 2218 UT. This onset coincided with the IMF $B_{z}$ component dropping to $-20 \mathrm{nT}$. The IMF then remained negative until $\sim 2235$ UT when it became strongly positive. Shortly after this at 2240 UT, there was intensification in the magnetic perturbations and $\mathrm{Pi} 2 \mathrm{~s}$ observed by IMAGE and SAMNET in the post-midnight sector, and a little later by Greenland east and Iceland in the pre-midnight sector. Particle injection signatures were also detected by the LANL satellites 1990-095 and 1984-124 at this time. The recovery phase commenced around 2340 UT.

We now turn to examine the flow data from the Goose Bay HF radar, located in the dusk sector to the west of the substorm disturbed region (see Fig. 7). A summary of the flow data deduced from this radar is presented in Fig. 9, where we show the vector flow 


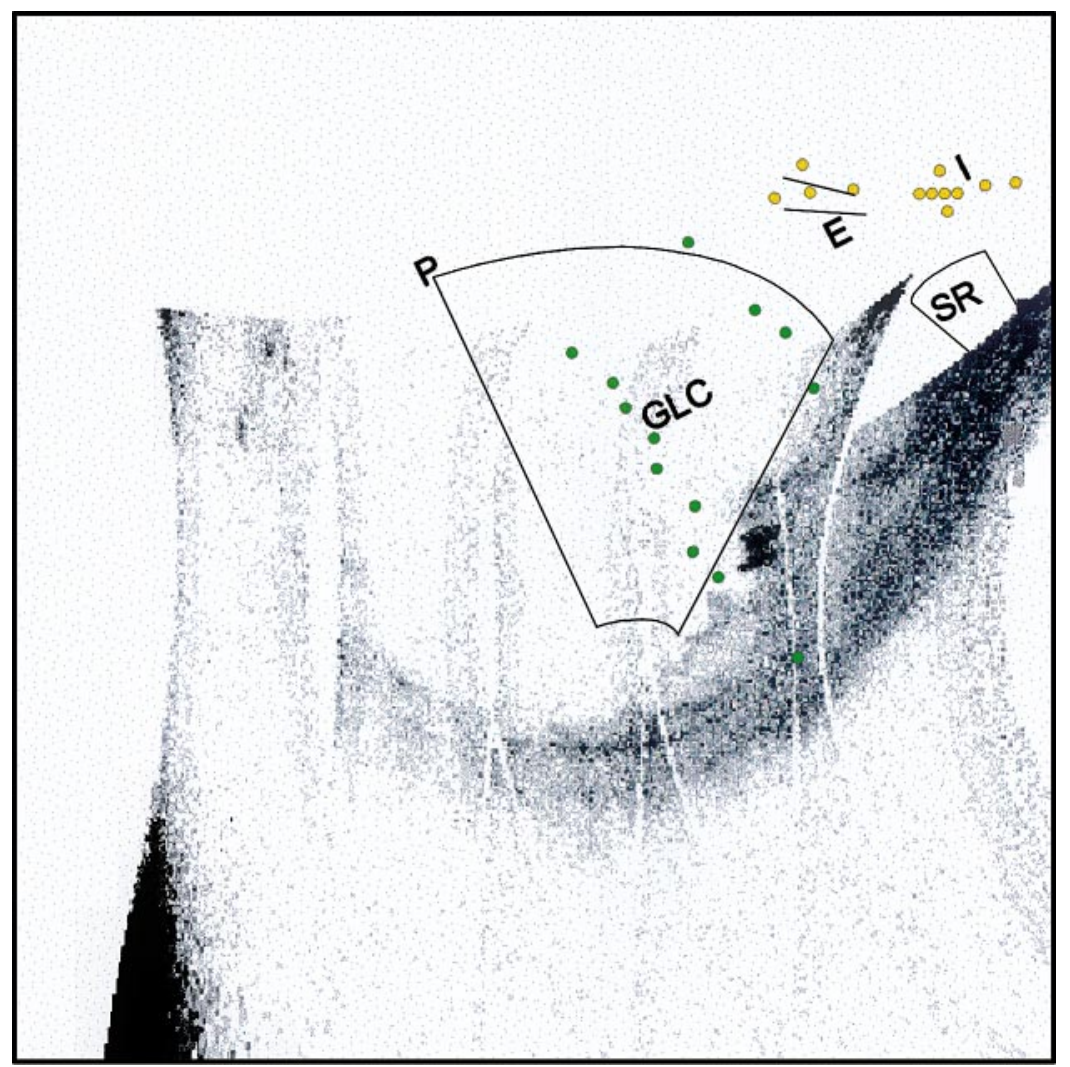

Fig. 7. A composite of five consecutive UV images taken from the Freja satellite (orbit 828) between 2329-2339 UT on 7 December, 1992. The image shows the auroral oval in the late expansion phase over Canada, Greenland and the north Atlantic. The fields-of-view of the Goose Bay, EISCAT and SABRE radars and the position of the SAMNET, IMAGE and Greenland magnetometer chains are overlaid. The $55^{\circ}$ line is geomagnetic latitude, and 19 is the magnetic local time, both calculated using the eccentric dipole model (IGRF 1992.937). The northern end of the 19 MLT line is the magnetic pole versus invariant latitude and time between 22 and 23 UT. The flow data are shown for beam 5 of the radar directed towards magnetic north. These data show mainly eastward flow in the poleward part of the fieldof-view and westward flow in the equatorward region, such that the convection reversal boundary (CRB) remains within the field-of-view for much of this interval. These data can thus be used to determine the latitudinal motion of the CRB during the substorm cycle. Under usual circumstances, this CRB will usually be located a little equatorward of the open/closed field line boundary if viscous flows are present, thus the motion of the CRB can be taken as a reasonable proxy for the motion of the open/closed field line boundary, allowing us to monitor the expansion and contraction of the polar cap in the dusk sector.

We have thus examined the vector velocities over the entire field-of-view of the radar (15 beams) and used the method described to find the invariant latitude of the CRB for the interval 2130-00 UT (1830-2100 MLT) as shown in Fig. 10. The lack of scatter, or of clear flow often makes identification of the CRB latitude difficult and the vertical error bars indicate these uncertainties. Following an initial equatorward motion between 2130 and 2135 UT, the CRB remained at $\sim 70^{\circ}$ until $\sim 2200$ UT (Fig. 10). An equatorward motion was then evident continuing across the onset of the substorm at 2215 UT and accelerating prior to the intensification at 2240 UT. This behaviour closely mirrors the behaviour of the backscatter band seen by the SABRE radar (Fig. 3) which showed a similar equatorward motion between 2200 and at least 2235 UT. From this we infer that the region of open magnetic flux continued to expand for $\sim 25$ min after substorm onset, presumably due to the fact that the IMF $B_{z}$ was $\sim-20 \mathrm{nT}$ during this period, such that the rate of reconnection on the dayside considerably exceeded that on the nightside. During this interval, therefore, typical signatures of both growth and expansion phases were simultaneously present. Following the substorm intensification at $\sim 2240$ UT (and northward turning of the IMF) the CRB within the Goose Bay field-of-view remained at a roughly constant latitude of $\sim 68^{\circ}$ until about 2305 UT when it appeared to jump poleward to $72^{\circ}$, where it remained located for the remainder of this interval. Given that there was a substorm intensification at 2240 UT together with the presence of northward IMF since 2235 UT, such that dayside reconnection will have been substantially reduced, it is perhaps surprising that the poleward contraction of the CRB at Goose Bay did not occur until 2305 UT. This point will be discussed later.

Another important feature of the Goose Bay flow data can also be seen in Fig. 9, in that there was a major change in the flow pattern at 2245 UT, from an eastward flow in the polar cap to strong northeast flows. These were observed for three consecutive $96 \mathrm{~s}$ scans until the backscatter from the poleward part of the field-of-view disappeared. An example of the velocities deduced over the whole radar field-of-view during this interval is shown in Fig. 11. Comparing Fig. 11 with the Freja image in Fig. 7, shows that the flows in the poleward region of the Goose Bay radar are in fact directed towards the poleward expanding substorm bulge near midnight. It seems reasonable to infer that these flows 

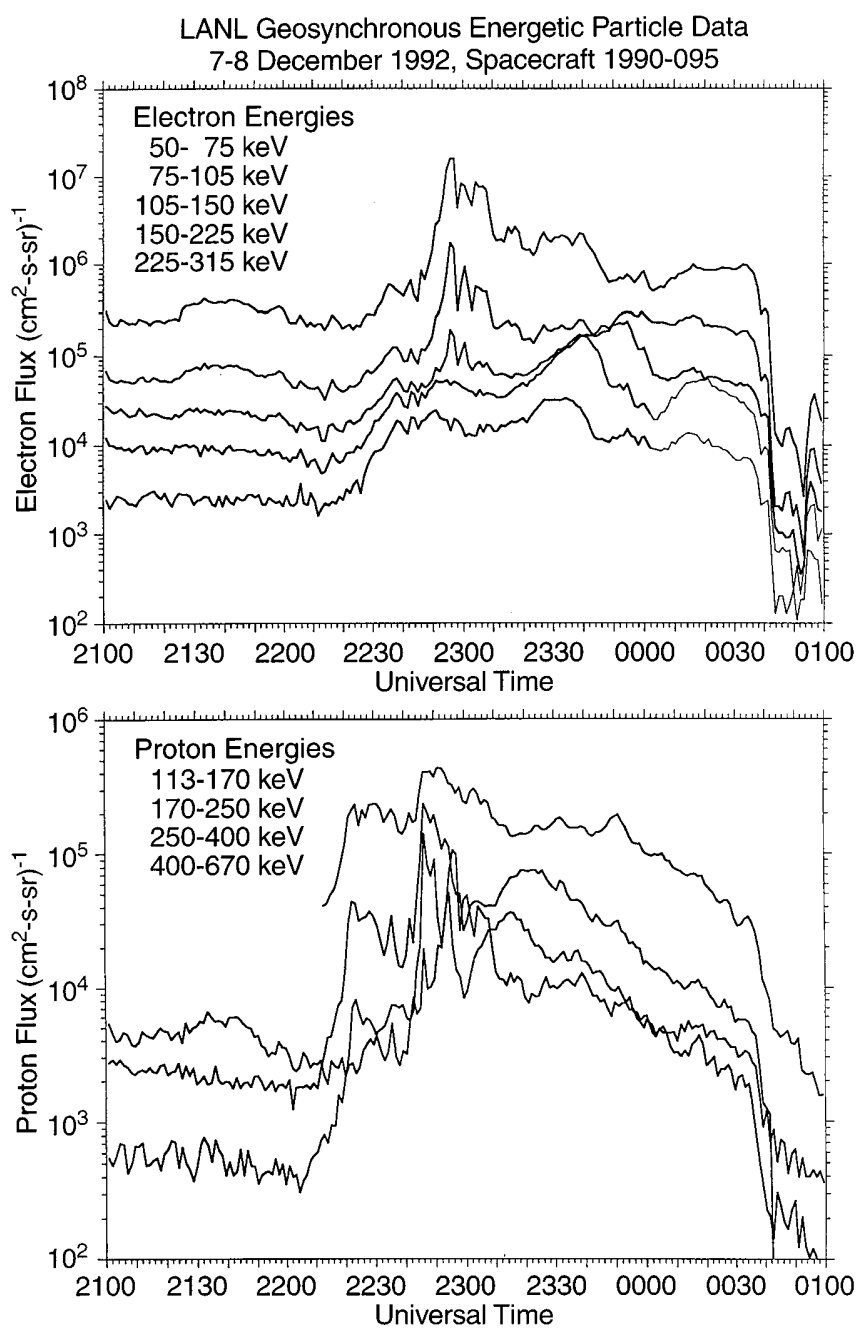

Fig. 8a, b. Geosynchronous energetic particle data for 21 UT, 7 December, 1992-01 UT, 8 December, 1992, from spacecraft 1990-095 (local time $=\mathrm{UT}+0031$ ). a Is energetic electron data and $\mathbf{b}$ is energetic proton data. The flux ranges are indicated to the left of the two panels

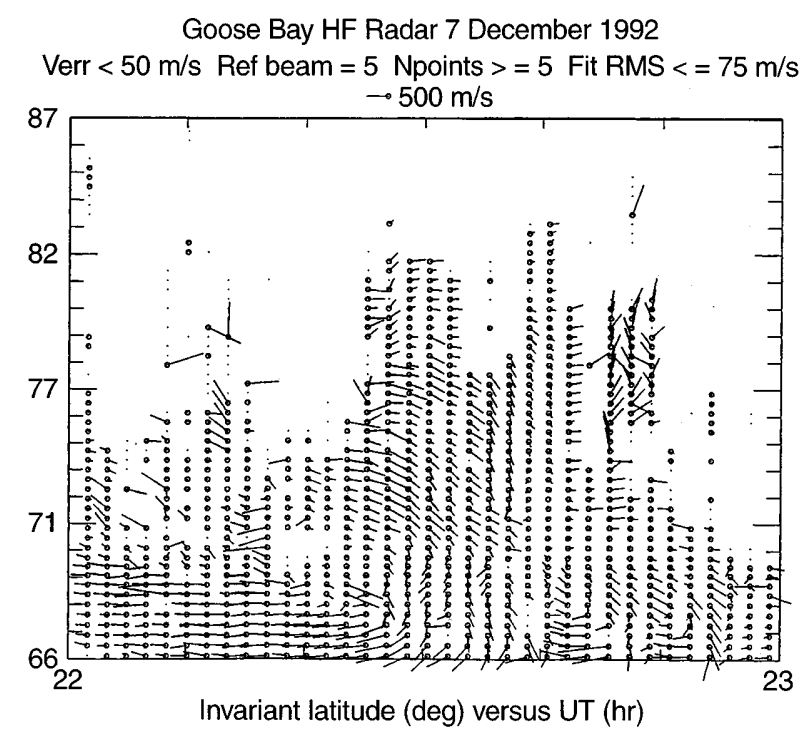

Fig. 9. Derived flow vectors for beam 5 of the Goose Bay radar plotted as a function of UT and invariant latitude for 22-23 UT were associated with the substorm intensification at 2240 UT, and were generated by the dipolarisation in the tail and subsequent closure of open flux (Cowley et al., 1998).

Additional information about the ionospheric flow and the motion of the CRB was provided by data from three passes across the northern polar cap by the DMSP satellites F10 and F11. These are shown in Fig. 12. The UT quoted on the plots corresponds to the time the satellites were closest to the pole during each pass. These were 2133 UT (Fig. 12a), corresponding to the interval just prior to the start of the growth phase, 2249 UT (Fig. 12b), shortly after the substorm intensification, and 2314 UT (Fig. 12c), corresponding to the late expansion phase, prior to the commencement of recovery. The position of the CRBs are listed in Table 1 as determined from the maximum and minimum values of the potential, together with the local time at which the boundary was detected and the UT when the observation was made. There are two passes of satellite F10 in the Northern Hemisphere (Fig. 12a, c) which fly through the 21 MLT meridian close to the field-of-view of the Goose Bay radar. The latitudes of the 21 MLT CRB for these orbits are plotted in Fig. 10. Early in the sequence in Fig. 10, at 2130 UT ( 18:30 MLT), the CRB seen by Goose Bay is at a similar latitude to that seen at 21:17 MLT by DMSP F10. At 2309 UT F10 observed the CRB at $21: 16 \mathrm{MLT}$ at $70.38^{\circ}$ in the Northern Hemisphere. The centre of the Goose Bay field-of-view is at 20:09 MLT at this time, i.e. the satellite was at a meridian one hour later in MLT. This therefore, is consistent with the minimum latitude estimate from the Goose Bay radar.

Turning now to the flow data shown in Fig. 12, it can be seen that the flow prior to the start of the growth phase contained surprisingly large flows on the nightside, possibly driven by reconnection in the distant tail. There is also evidence of an anti-clockwise vortex in the polar cap possibly driven by lobe reconnection in the presence of IMF $B_{y}$ negative and $B_{z}$ positive (Fig. 2). At 2249 UT, as shown in Fig. 12b, the IMF had returned to almost similar values but now the dayside flows show a well-developed twin-vortex pattern. The presence of these strong dayside flows implies that they were being driven by nightside reconnection and consequent poleward contraction of the open/closed field line boundary associated with the substorm intensification at 2240 UT. Again strong dayside flows are shown in Fig. 12c, with anti-Sunward flow in the polar cap. Given that the IMF $B_{z}$ is inferred from Fig. 2 to have been weakly negative but with a very strong negative $B_{y}$ at this time, these flows were likely to be driven by dayside reconnection as indicated by the strong eastward flows near noon, together with some possible continuing contribution from the nightside.

Flow vectors near midnight corresponding to the period just prior to the growth phase (21252155 UT $=$ MLT $\sim 23: 55-00: 25$ ) derived from the EISCAT radar observations are shown in Fig. 13. These vectors were derived using the "beam-splitting" technique described in Sect. 2. Note that to avoid conges- 


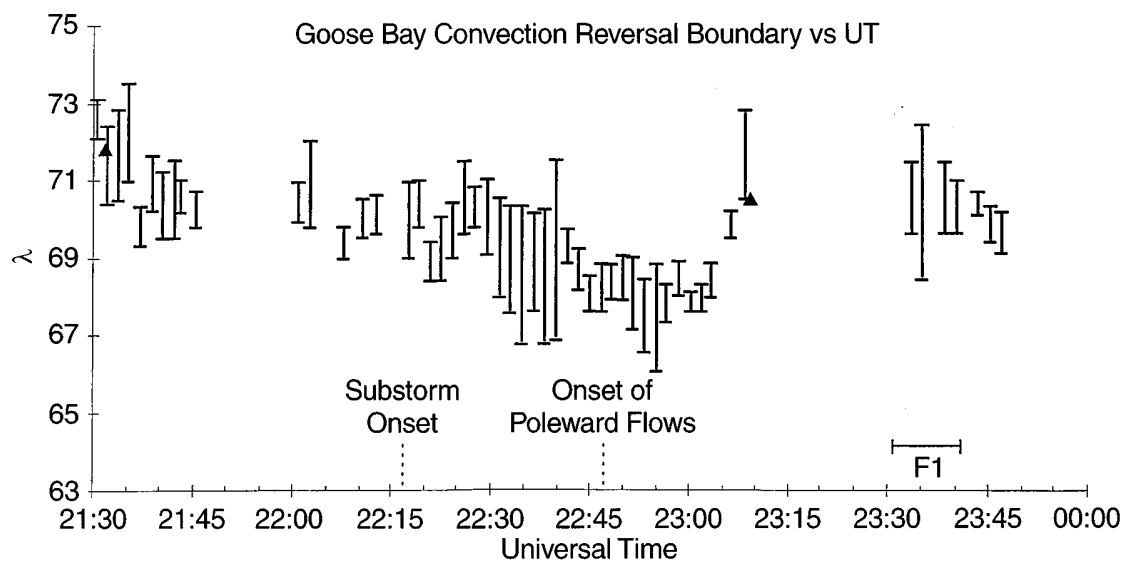

Fig. 10. Graph showing the latitudinal position of the CRB deduced from consecutive "fan" plots of Goose Bay data plotted against time. The latitude of the poleward UV auroral boundary is marked for Freja orbit 828 as F1 and the latitude of the CRB as determined from the DMSP-F10 data are denoted by solid triangles. The times of substorm onset and the start of enhanced poleward flows detected by the Goose Bay radar are also indicated tion, the vectors have been rotated clockwise through $90^{\circ}$ so northward flows appear as vectors pointing to the right of the figure. At the start of the interval, the dusk cell CRB is apparent as a rotation of the flow from eastward and equatorward in the poleward part of the field-view, to westward and equatorward in the lower latitude region. This reversal took place at about $72.7^{\circ}$ invariant latitude which is in good agreement with the location of the CRB observed in the dusk sector at this time by both the Goose Bay radar (Fig. 10) and the DMSP satellite F10 (Fig. 12a). After 2140 UT, however, the flows become variable, but predominantly eastward until 2327 UT over the entire field-of-view. The relationship of these flows to the position of the open/closed field line boundary is unclear during the first part of this interval, but at 2250 UT the effects of

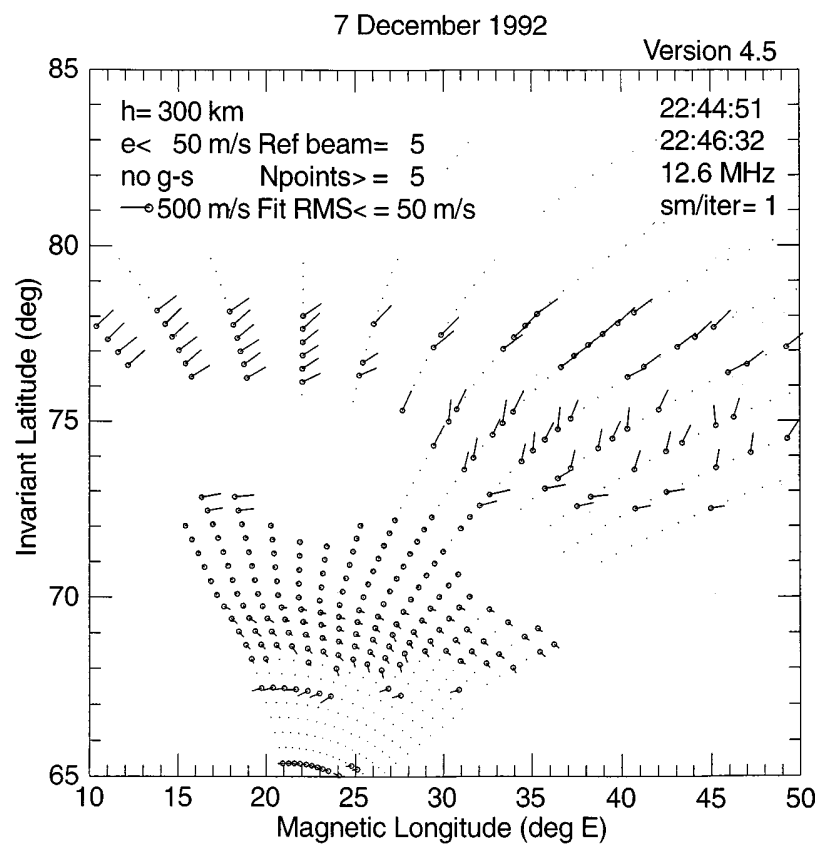

Fig. 11. Vectors showing direction and magnitude of the flow in the ionosphere deduced from the SuperDARN radar data at Goose Bay, for the scan 22:44:51-22:46:32 UT - the time corresponding to the onset of poleward flows. The fan represents the field-of-view as shown in Fig. 1 the substorm bulge were observed expanding poleward across the radar beams, clearly establishing the radar field-of-view as being on closed field lines after that time. Data for this interval are not shown as they will be the subject of a further paper together with the detailed observations of this poleward expansion. Subsequently the dawn CRB propagated equatorward across the fieldof-view starting at the furthest range gate at 2327 UT and reaching the nearest range gate just before 2339 UT. This established westward flow across the field-of-view. We interpret this motion as the equatorward relaxation of the substorm bulge in the immediate post-midnight sector, corresponding to the onset of substorm recovery.

\section{Discussion}

We have discussed an interval of substorm activity using multipoint observations encompassing a broad range of latitude and local time in the nightside sector. The growth phase appears to have been initiated by a southward turning of the IMF which reached the nose of the magnetosphere at 2140 UT as inferred from magnetosheath data from the Galileo spacecraft. The production of open flux lead to an expansion of the polar cap which was observed as an equatorward motion of the CRB in the Goose Bay radar field-ofview and an equatorward expansion of the SABRE backscatter band starting at about 2200 UT. A schematic of the flow configuration expected at this time is shown in Fig. 14, based on the theoretical models of Cowley and Lockwood (1992). The lines with arrows show the plasma stream lines. Those without arrows show the open-closed field line boundary, where the solid portion indicates the adiaroic section and the dashed portion the merging gap. The large arrows indicate the motion of the open-closed field line boundary. The flows are shown as being driven by steady unbalanced dayside reconnection with the open/ closed field line boundary expanding equatorward at all local times. We also show the possible co-existence of viscously-driven flow cells at latitudes lower than that of the open/closed field line boundary.

Substorm expansion phase onset occurred at 2215 UT, at which time the IMF became even more strongly 

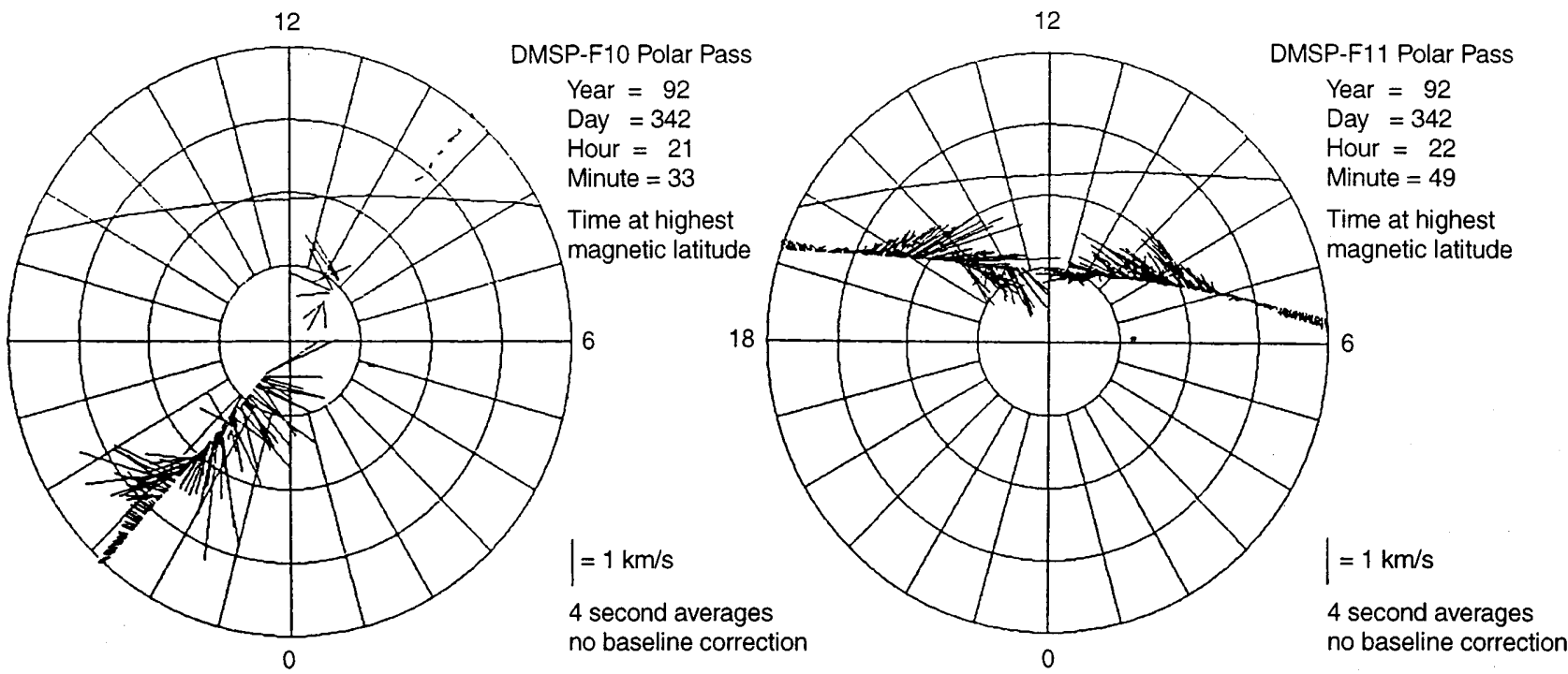

Magnetic Local Time and Magnetic Latitude Northern Hemisphere

Magnetic Local Time and Magnetic Latitude

a

b Northern Hemisphere

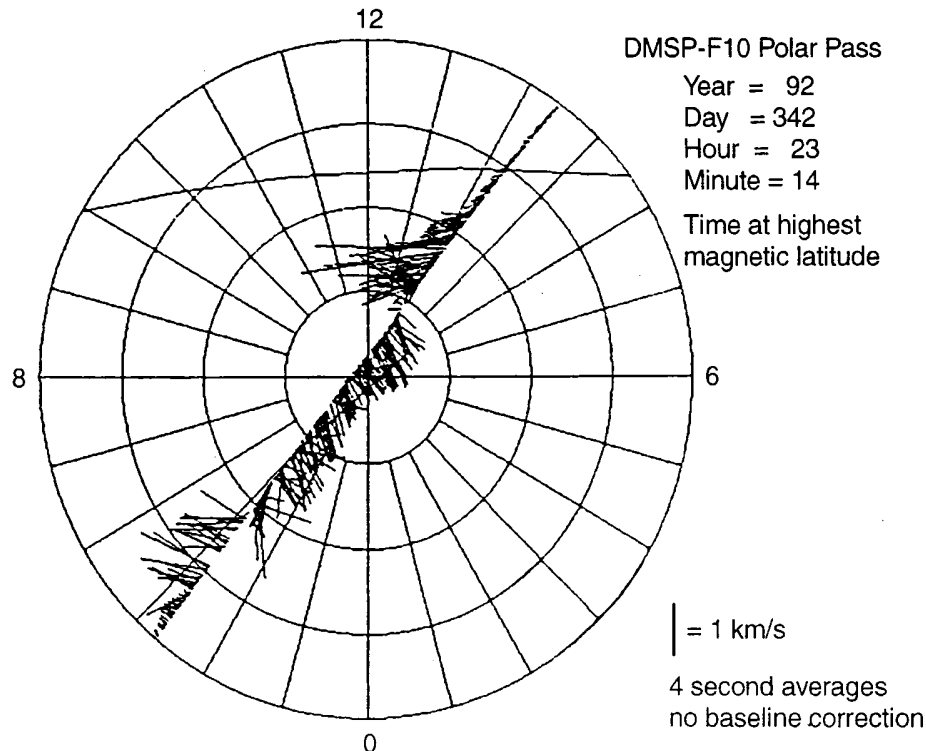

Magnetic Local Time and Magnetic Latitude Northern Hemisphere

c

southward at the subsolar magnetopause for an interval of $20 \mathrm{~min}$. This initial disturbance at the IMAGE chain was observed to be centred at $62^{\circ}$ latitude (station PEL) and reached poleward to station SOR at $66^{\circ}$ but was absent at $70^{\circ}$ (station $\mathrm{BJO}$ ). Since the evidence we have presented above from both the EISCAT radar in the
Fig. 12a-c. Ionospheric flow data from polar passes of the DMSP satellites F10 and F11 for the period 2133-2314 UT, 7 December, 1992. The plots are for Northern Hemisphere passes and are arranged in chronological order regardless of which satellite they represent midnight sector and the Goose Bay and DMSP data in the pre-midnight sector suggest that the open/closed field line boundary was located poleward of $70^{\circ}$ at this time, this implies that the onset substorm disturbance was confined to closed field lines and thus did not reach the pre-existing open-closed field line boundary.

Table 1. The latitudinal position of the CRB, the local time location and the UT at which it was detected are indicated in this table, for consecutive polar passes of satellites F10 and F11 in the Northern Hemisphere

\begin{tabular}{llllllrr}
\hline Satellite & Fig. 12 & UT & MLT & Magnetic latitude & UT & MLT & Magnetic latitude \\
\hline F10 & a & $21: 30$ & $21: 17$ & $71.67^{\circ}$ & $21: 37$ & $9: 14$ & $82.01^{\circ}$ \\
F11 & b & $22: 44$ & $15: 51$ & $70.22^{\circ}$ & $22: 52$ & $9: 21$ & $78.70^{\circ}$ \\
F10 & c & $23: 09$ & $21: 16$ & $70.38^{\circ}$ & 23.17 & $10: 11$ & $81.64^{\circ}$ \\
\hline
\end{tabular}


Experiment : SP-UK-CONV

Time Interval : 21:25:0 7 December 1992 - 21:55:00 7 December 1992

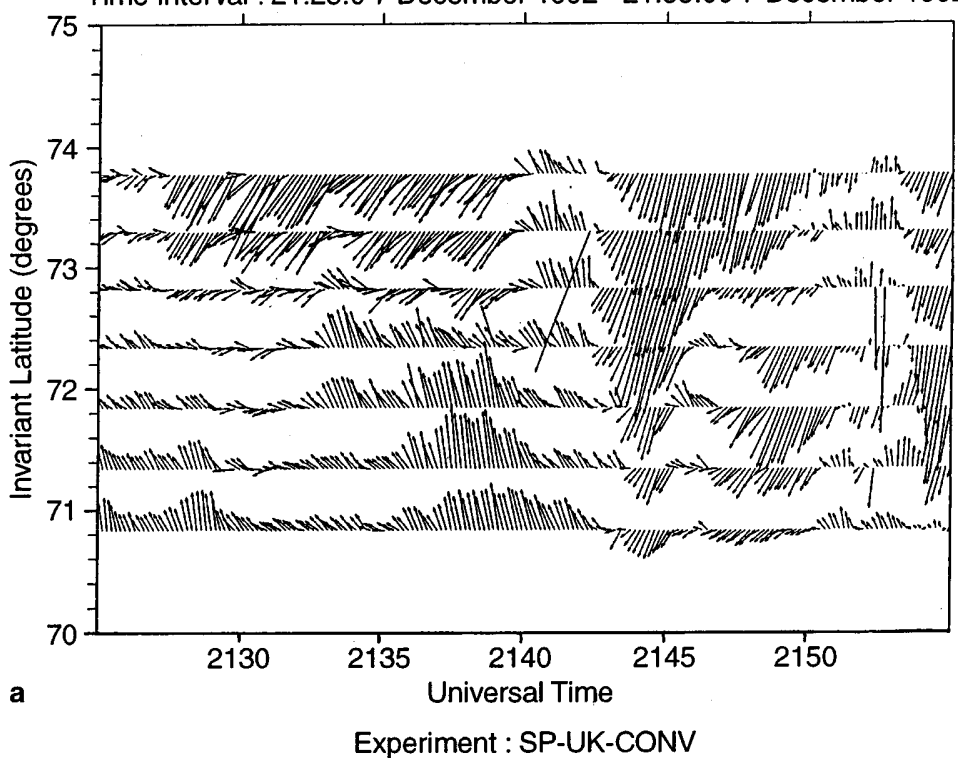

Time Interval : 22:40:0 7 December 1992 - 23:10:00 7 December 1992

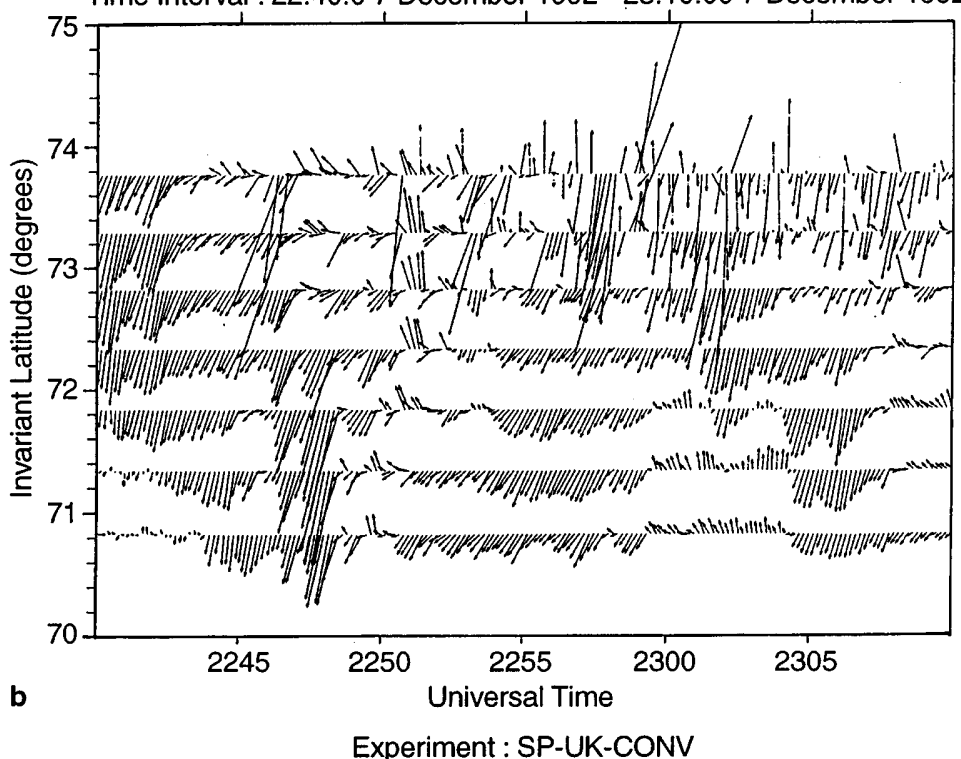

Time Interval : 23:10:0 7 December 1992 - 23:40:00 7 December 1992

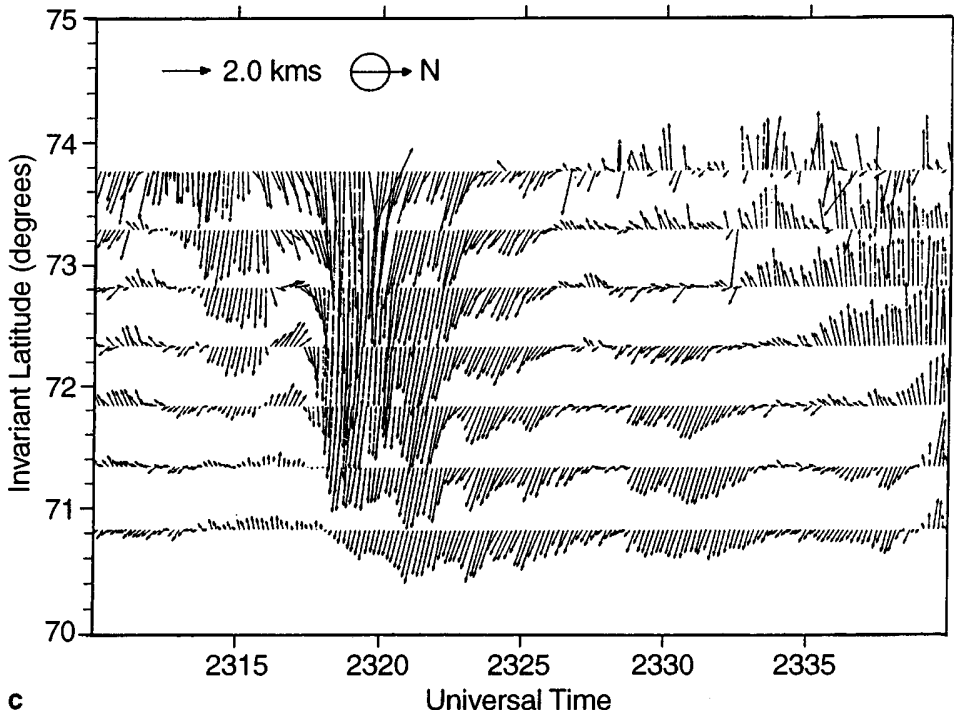

Fig. 13a-c. The three panels show the vectors deduced from the EISCAT CP-4-B experiment, which represent the velocity and direction of flow in the ionosphere. The vectors are rotated clockwise through $90^{\circ}$ in order to reduce the congestion of the predominantly east/west flows. The panels are for time intervals a 2125-2155 UT, b 2240-2310, and c 2310-2340 UT, 7 December, 1992 
a 12

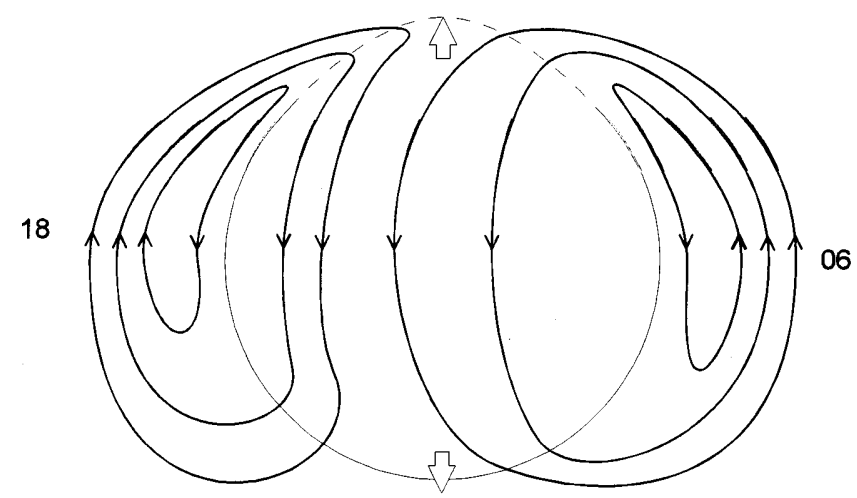

24

b

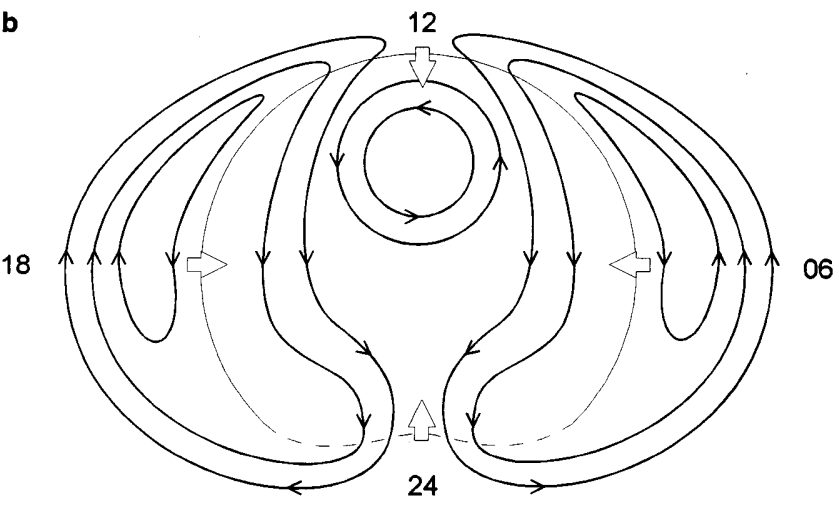

c

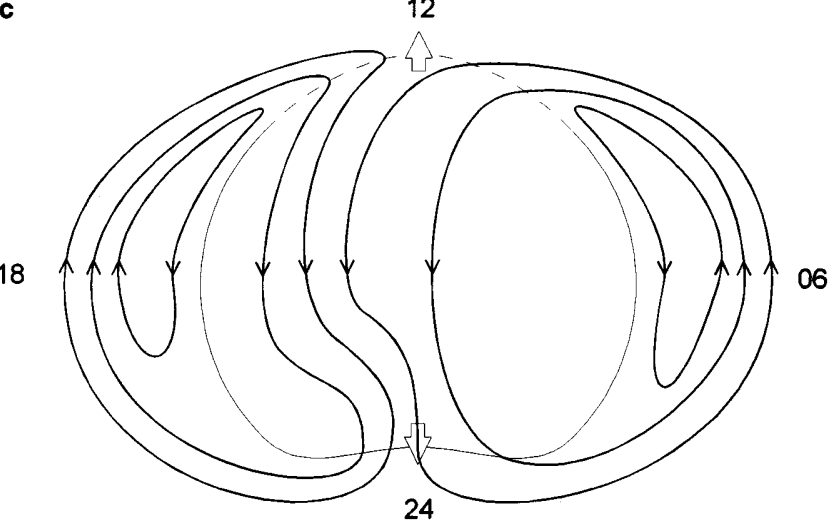

Fig. 14a-c. Schematics of convection patterns and boundary motions during the substorm cycle described based on theoretical models of Lockwood (1990) and Cowley and Lockwood (1992). In each of the three plots, the merging gaps are indicated by dashed lines and the large arrows indicate the boundary movement. a Shows the scene after 2215 UT, when substorm onset signatures were detected and the IMF $B_{z}$ field has decreased to $-20 \mathrm{nT}$. Although this disturbance may have involved an interval of reconnection, we infer that no open flux was closed, and hence the polar cap area continues to expand. b Represents the flows after the IMF $B_{z}$ has turned northward. A lobe cell is present - the direction of circulation determined by the negative $B_{y}$ field. Enhanced nightside flows are shown driven by tail reconnection, consistent with the poleward flows detected by the Goose Bay radar at high latitudes. The strong flows are seen in the dayside sector driven by the contraction of the open/closed field line boundary. c Shows the scenario during the substorm recovery phase with the equatorward relaxation of the boundary in the midnight sector, together with the weaker poleward motions elsewhere. Asymmetric flow on the dayside is present as detected by the DMSP F10 satellite (Fig. 12c)
Although this disturbance may have involved an interval of reconnection in the near-Earth tail, we infer that it did not involve the closure of open flux. Consistent with this, the CRB at Goose Bay and the backscatter band at SABRE continued to expand equatorward after onset; indeed this motion was intensified after onset, presumably associated with the strongly enhanced negative IMF $B_{z}$ that was present during this time. The flow pattern is, therefore, likely to be similar to that shown in Fig. 14a, except that the flow speeds may be enhanced, as seen by the Goose Bay radar shown in Fig. 9. There may also be nightside flow perturbations mainly on closed field lines associated with the dipolarisation of the tail field (Cowley et al., 1998), although we have no direct data to support this.

Despite the absence of open flux closure during the initial expansion phase, the later substorm intensification at 2240 UT clearly did involve substantial closure of open flux. We infer that open flux was closed because firstly the magnetic disturbance reached high magnetic latitudes up to $75-77^{\circ}$ on the IMAGE and Greenland east chain, latitudes that considerably exceeded that of the CRB at both Goose Bay and EISCAT seen prior to substorm expansion. Second, we observed a region of strong poleward flow directed towards the midnight sector in the polar cap in the Goose Bay radar field-ofview. A composite of the radar flow observations is shown in Fig. 15, comprising vectors from both the EISCAT and Goose Bay radars at 2245 UT. A schematic of the flows occurring at this time consistent with these observations is shown in Fig. 14b. These show the presence of enhanced nightside flows driven by tail reconnection consistent with the poleward flows seen in the higher latitude region of the Goose Bay radar in the dusk sector. These strong flows continue

\section{Radar Map}

Goose Bay 7 December 1992

Time: $22: 44: 51$, Freq: $12.5 \mathrm{MHz}$, Alt: $300.0 \mathrm{~km}$ Thresh: PWR $\leftarrow$ L $(-60.0-60.0)$. Param: VEL/ALL

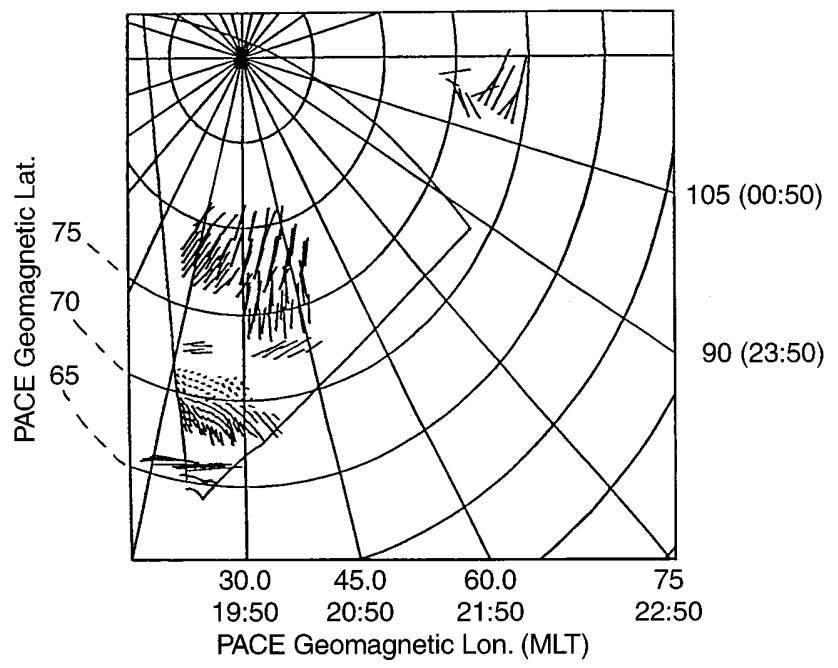

Fig. 15. EISCAT and SuperDARN flow vectors at 22:44:51 UT the time of onset of the poleward flows seen at Goose Bay 
into the dayside sector driven by the contraction of the open/closed field line boundary as observed by the DMSP F11 spacecraft. The schematic also shows a possible anti-clockwise lobe cell vortex which may be driven by the IMF $B_{y}$ negative and $B_{z}$ positive which was present at this time. This pattern provides a possible explanation of the sudden poleward motion of the CRB observed at Goose Bay at 2305 UT. Prior to this time, the observed CRB may have been located in the viscous cell on closed field lines. At 2305 UT the radar could then have moved into the flow cell region driven by nightside reconnection such that the observed CRB would be located much closer to the open/closed field line boundary, as shown in Fig. 14b. A schematic of the recovery phase is shown in Fig. 14c which is related to equatorward relaxation motion of the boundary in the midnight sector as observed by EISCAT and weaker poleward motions elsewhere. In addition, asymmetric flow is also shown as being driven on the dayside during this interval by open flux production associated with the weaker southward IMF with $B_{y}$ negative which was again present during this interval, as indicated by the DMSP data in Fig. 12c.

\section{Conclusions}

We have examined observations over a substorm cycle from a variety of data sources located over $6 \mathrm{~h}$ of local time in the nightside sector. The observations from the Goose Bay and SABRE radars have enabled us to investigate the behaviour of the dusk convection cell while the EISCAT radar and IMAGE magnetometer chain simultaneously detected activity in the immediate post-midnight sector. The onset and development of the substorm were monitored by the IMAGE and Greenland magnetometer chains, $\mathrm{Pi} 2$ data at midlatitudes, and energetic particle data from two geosynchronous satellites. The IMF conditions for this interval were determined by the data from the Galileo satellite in the nightside magnetosheath. There was an initial growth phase of about $30 \mathrm{~min}$ during which the IMF $B_{z}$ component was $\sim-5$ to $10 \mathrm{nT}$. The $B_{z}$ component subsequently dropped to $-20 \mathrm{nT}$ in concert with the substorm expansion phase onset signatures. IMF $B_{z}$ then remained at this large negative value for another 20 min until it suddenly turned to a positive value of $\sim 20 \mathrm{nT}$. This northward turning occurred shortly before a substorm intensification, and commencement of the CRB contraction. The recovery phase commenced at around 2340 UT.

The most important results that we have found from our study are as follows. Firstly, the substorm onset electrojet was confined to closed field lines equatorward of the pre-existing CRBs observed by the Goose Bay and EISCAT radars. No evidence of substantial closure of open flux was observed following this substorm onset. Indeed the CRB in the duskside continued to expand equatorward following onset due to the continued presence of strong southward IMF, such that growth and expansion phase features were simultaneously present. Clear indications of closure of open flux were not observed until after the subsequent intensification at 2240 UT, i.e. more than 25 min after the initial onset. After this time, the substorm auroral bulge in the nightside hours propagated well poleward of the preexisting CRB, and strong flow perturbations were observed by the Goose Bay radar, indicative of flows driven by reconnection in the tail. These data thus provide strong evidence that the closure of open flux in the tail can be delayed significantly relative to the onset of the substorm expansion phase.

Acknowledgements. NJF wishes to acknowledge the support of a National Research Council Award. This work was supported in part by NASA/International Solar Terrestrial Physics Mission grants - NAG5-7260 and NAG5-8361. The authors wish to thank the EISCAT Association and the teams supporting the SABRE and SuperDARN Goose Bay radars. GDR was supported by the US Department of Energy Office of Basic Energy Research. Galileo magnetic field data was kindly provided by M. G. Kivelson and D. J. Southwood. The authors would also like to thank T. K. Yeoman, R. J. Barnes and B. Shand for their help in the production of the figures.

Topical Editor D. Alcaydé thanks J. M. Bosqued and A. G. Yahnin for their help in evaluating this paper.

\section{References}

Akasofu, S.-I., The development of the auroral substorm, Planet. Space Sci. 12, 273-282, 1964.

Baker, D. N., P. R. Higbie, E. W. Hones Jr., and R. D. Belian, High-resolution energetic particle measurements at 6.6 RE 3. Low-energy electron anisotropies and short-term substorm predictions, J. Geophys. Res., 83, 4863, 1978.

Belian, R. D, G. R. Gisler, T. Clayton, and R. Christensen, High Z energetic particles at geosynchronous orbit during the great solar proton event of October 1989, J. Geophys. Res., 97, 16897, 1992.

Cogger, L. L., and R. D. Elphinstone, The Viking auroral substorm, in International Conference on Substorms-1, ESA SP-335, Noordwijk, The Netherlands, 77, 1992.

Cowley, S. W. H., and M. Lockwood, Excitation and decay of solar wind-driven flows in the magnetosphere-ionosphere system, Ann. Geophysicae, 10, 103, 1992.

Cowley S. W. H., H. Khan, and A. Stockton-Chalk, Plasma flow in the coupled magnetosphere-ionosphere system and its relationship to the substorm cycle, in Substorms-4, Eds. S. Kokubun, and Y. Kamide, Terra Academic Publishing Company/Kluwer Academic Publishers, 623, 1998.

Elphinstone, R. D., and D. J. Hearn, Mapping of the auroral distribution during quiet times and substorm recovery, in International Conference on Substorms-1, ESA SP-335, Noordwijk, The Netherlands, 13, 1992.

Freeman, M. P., J. M. Ruohoniemi, and R. A. Greenwald, The determination of time-stationary two-dimensional convection patterns with single-station radar, J. Geophys. Res., 96, 15 735, 1991.

Friis-Christensen, E., Y. Kamide, A. D. Richmond, and S. Matsushita, Interplanetary magnetic field control of high-latitude ionospheric fields and currents determined from Greenland magnetometer data, J. Geophys. Res., 90, 1325, 1985.

Galperin, Y. I., and Y. I. Feldstein, Auroral luminosity and its relationship to magnetospheric plasma domains, in Auroral Physics, Eds. C.-I. Meng, M. J. Rycroft, and L. A. Frank, Cambridge University Press, Cambridge, UK, 207, 1991.

Greenwald, R. A., K. B. Baker, R. A. Hutchins, and C. Hanusie, An HF phased-array radar for studying small-scale structure in the high-latitude ionosphere, Radio Sci., 20, 63, 1985. 
Greenwald, R.A., K. B. Baker, J. R. Dudeney, M. Pinnock, T. B. Jones, E. C. Thomas, J. -P. Villian, J. -C. Cerisier, C. Senior, C. Hanuise, R. D. Hunsucker, G. Sofko, J. Koehler, E. Nielsen, R. Pellinen, A. D. M. Walker, N. Sato, and H. Yamgishi, DARN/ SUPERDARN; a global view of the dynamics of high-latitude convection, Space Sci. Rev., 71, 761, 1996.

Higbie, P. R., R. D. Belian, and D. N. Baker, High-resolution energetic particle measurements at $6.6 \mathrm{R}_{\mathrm{E}} 1$, Electron micropulsations, J. Geophys. Res., 83, 4851, 1978.

Hones, E. W. Jr., Transient phenomena in the magnetotail and their relation to substorms, Space Sci. Rev., 23, 393, 1979.

Inhester, B., W. Baumjohann, R. A. Greenwald, and E. Nielson, Joint two-dimensional observations of ground magnetic and ionospheric electric fields associated with auroral zone currents, 3. Auroral zone currents during the passage of a westward travelling surge, J. Geophys. Res., 86, 155, 1981.

Kivelson, M. G., K. K. Khurana, J. D. Means, C. T. Russell, and R. C. Snare, The Galileo magnetic field investigation, Space Sci. Rev., 60, 357, 1992.

Lester, M., O. de la Beaujardière, J. C. Foster, M. P. Freeman, H. Lühr, J. M. Ruohoniemi and W. Swider, The response of the large scale ionospheric convection pattern to changes in the IMF and substorms: results from the SUNDIAL 1987 campaign, Ann. Geophysicae, 11, 11 556, 1993.

Lockwood, M., On flow reversal boundaries and transpolar voltage in average models of high latitude convection, Planet. Space Sci., 39, 397-409, 1990.

Lopez, R. E., H. E. Spence, and C.-I. Meng, Substorm aurorae and their connection to the inner magnetosphere, J. Geomag. Geoelectr., 44, 1251, 1992.

Lühr, H., A. Aylward, S. C. Buchert, A. Pajunpaa, K. Pajunpaa, T. Holmboe, and S. M. Zalewski, Westward moving dynamic substorm features observed with the IMAGE magnetometer network and other ground-based instruments, Ann. Geophysicae, 16, 425, 1998.

Mattin, N., and T. B. Jones, SABRE observations of F-region vertical velocity structures, J. Atmos. Terr. Phys., 48, 625, 1986.
Maynard, N. C., W. J. Burke, G. M. Erickson, M. Nakamura, T. Mukai, S. Kokubun, T. Yamamoto, B. Jacobsen, A. Egeland, J. C. Samson, D. R. Weimer, G. D. Reeves, and H. Lühr, Geotail measurements compared with the motions of high-latitude auroral boundaries during two substorms, J. Geophys. Res., 102, 9553, 1997.

McPherron, R. L., Growth phase of magnetic substorms, J. Geophys. Res., 75, 5592, 1970.

Murphree, J. S., and L. L. Cogger, Observations of substorm onset, in International Conference on Substorms-1, ESA SP-335, Noordwijk, The Netherlands, 207, 1992.

Murphree, J. S., R. A. King, T. Payne, K. Smith, D. Reid, J. Adema, B. Gordon, and R. Wlochowicz, The Freja ultraviolet imager, Space Sci. Rev., 70, 421, 1994.

Nagai, T., M. Fujimoto, Y. Saito, S. Michida, T. Terasawa, R. Makamura, T. Yamamoto, T. Mukai, A. Nishida, and S. Kokubun, Structures and dynamics of magnetic reconnection for substorm onsets with Geotail observations, J. Geophys. Res., 103, 4419, 1998.

Nielsen, E., W. Güttler, E. C. Thomas, C. P. Stewart, T. B. Jones, and A. Hedberg, A new radar auroral backscatter experiment, Nature, 304, 712, 1983.

Ruohoniemi, J. M., R. A. Greenwald, K. B. Baker, J-P. Villian, and J. Kelly, Mapping high-latitude plasma convection with coherent HF radars, J. Geophys. Res., 94, 13 463, 1989.

Taylor, J. R., T. K. Yeoman, M. Lester, B. A. Emery, and D. J. Knipp, Variations $\mathrm{n}$ the polar cap area during intervals of substorm activity on March 20-21 1990 deduced from AMIE convection patterns, Ann. Geophysicae, 14, 879, 1996.

Wilhjelm, J., and E. Friis-Christensen, Electric fields and highlatitude zonal currents induced by merging of field lines, Geophys. Pap. R-31, Dan. Meteorol. Inst., Charlottenlund, Denmark, 1976.

Yeoman, T. K., M. Lester, D. Orr, and H. Lühr, Ionospheric boundary conditions of hydromagnetic waves: The dependence on azimuthal wave number and a case study, Planet. Space Sci., 38, 1315, 1990. 